\title{
In vitro formation of short RNA polymerase II transcripts that terminate within the HIV-1 and HIV-2 promoter- proximal downstream regions
}

\author{
Mark G. Toohey and Katherine A. Jones ${ }^{1}$ \\ Molecular Biology and Virology Laboratory, The Salk Institute, La Jolla, California 92037 USA
}

\begin{abstract}
Trans-activation of HIV-1 transcription by the viral regulatory protein Tat has been proposed recently to overcome a block to RNA polymerase II elongation in vivo imposed by 5 '-untranslated leader sequences. Interestingly, however, only full-length transcripts, rather than prematurely terminated HIV RNAs, are synthesized in most cell-free transcription extracts. Here, we describe an in vitro system in which induction of a highly efficient RNA polymerase II termination or cotranscriptional RNA processing event creates short HIV RNAs with 3' ends that map to a region immediately downstream of the HIV-1 or HIV-2 promoters. Termination in vitro is sequence dependent, generating short HIV-1 RNAs of 58-61 nucleotides that resemble in vivo transcripts observed in the absence of Tat, and a distinct, longer transcript of $\sim 125-130$ nucleotides from the HIV-2 promoter. Deletion of promoter-proximal HIV-2 downstream sequences results in the loss of a discrete RNA but also fails to restore wild-type transcription, indicating that termination actually is specified at the promoter and occurs at a site positioned by one or more elements located immediately upstream of the 3 ' end of the short RNAs. Experiments with recombinant HIV-2 promoters and nucleoside analogs indicate that this event involves a concerted interaction between the promoter and orientation-dependent leader sequences and that RNA secondary structure formation may also be required. These data provide direct evidence for abbreviated HIV transcripts and an in vitro approach to understanding the roles of cellular and viral regulatory proteins that mediate this process at the HIV promoters.
\end{abstract}

[Key Words: Human immunodeficiency viruses; RNA termination mechanisms; downstream control elements; in vitro transcription system]

Received December 7, 1988; revised version accepted January 23, 1989.

Premature termination of transcription, a common mechanism of transcriptional control in prokaryotes, has been increasingly implicated in the regulated expression of eukaryotic genes. Although much progress has been achieved in understanding authentic termination and polyadenylation processing steps for RNA polymerase II transcripts, less is known about the signals that specify pausing and premature termination (for reviews, see Birnstiel et al. 1985; Platt 1986; Friedman et al. 1987). Studies using either nuclear transcription extracts or highly purified protein preparations have shown that RNA polymerase II transit through a gene can be impeded by T-rich stretches located on the sense strand (Baek et al. 1986; Dedrick et al. 1987; Reines et al. 1987). It is likely, however, that premature termination of RNA polymerase II transcription may be achieved by several distinct mechanisms. For example, termination within the first intron of the human c-myc gene, which is induced upon differentiation of promyeloid cell lines to granulocytes (Bentley and Groudine 1986; Eick and Bornkamm 1987), is not influenced by T-rich sequences

${ }^{1}$ Corresponding author. at the site of the terminated RNA transcripts but depends instead on sequences upstream of the termination site (Bentley and Groudine 1988). Efficient termination at the c-myc promoter can be detected in injected Xenopus oocytes (Bentley and Groudine 1988) or in HeLa nuclear transcription extracts (Chung et al. 1987). A distinct type of termination event occurs within the 5 -untranslated leader region of the adenovirus- 2 major late promoter (AdMLP) at late times during viral infection (Mok et al. 1984). In contrast to c-myc transcription, termination at the adenovirus site can be detected in vitro only if extracts are fractionated extensively or treated with relatively high concentrations of the anionic detergent sarkosyl, suggesting that cellular antiterminators may be selectively inactivated in vivo to regulate termination at this promoter (Hawley and Roeder 1985, 1987; Reinberg and Roeder 1987).

Another system in which premature termination of transcription has been invoked is in the regulated expression of the human immunodeficiency viruses (HIVs). Transcription from either the HIV-1 or HIV-2 promoters is induced dramatically by the HIV-1 Tat protein (Cullen 1986; Peterlin et al. 1986; Wright et al. 
1986; Emerman et al. 1987; Muesing et al. 1987) as well as by different viral and cellular trans-activation mechanisms (Davis et al. 1987; Nabel and Baltimore 1987; Tong-Starksen et al. 1987). To date, the HIV-1 and HIV-2 promoters provide the only models for Tat action, as no other viral or cellular Tat-responsive genes have been identified. Regulation by Tat requires a downstream control region that functions in an orientation- and position-dependent manner and is somewhat more active in conjunction with the HIV promoter than when positioned downstream of heterologous promoters (Rosen et al. 1985; Cullen 1986; Peterlin et al. 1986; Hauber and Cullen 1988; Jakobovitz et al. 1988). Whether Tat acts directly on the promoter remains unclear, as purified preparations of Tat demonstrate a significant affinity for nucleic acid (Frankel et al. 1988) but have not yet been shown to interact specifically with the trans-activation target site in either DNA or RNA form. Nuclear run-on experiments in COS cell nuclei revealed that RNA synthesis from the HIV-1 promoter generates only short transcripts of $\sim 55-59$ nucleotides in the absence of Tat (Kao et al. 1987). Introduction of Tat by cotransfection led to the synthesis of full-length RNA transcripts, indicating that Tat may act as a sequence-specific antiterminator of transcription. If antitermination at the HIV-1 promoter is a major component of regulation by Tat, it must be a complex process, however, because removal of the downstream region containing the termination site does not restore promoter activity in vivo and because fusion of HIV-1 leader sequences to heterologous promoters generally does not lower basal levels of transcription (Rosen et al. 1985; Cullen 1986; Peterlin et al. 1986; Wright et al. 1986; Muesing et al. 1987). These results, taken together with observations that heterologous promoter constructs also do not respond strongly to Tat (Cullen 1986; Peterlin et al. 1986) suggest that termination efficiency might be coupled to the structure and activity of the HIV promoters.

Our interest has been to investigate the mechanism of HIV promoter function by in vitro approaches. The structure of the HIV-1 promoter required for trans-activation includes two enhancer repeats that bind NF- $\mathrm{KB}$ in phorbol-ester-treated cells, or EBP-1 in resting cells (Dinter et al. 1987; Nabel and Baltimore 1987; Kawakami et al. 1988; Wu et al. 1988). Adjacent to the enhancer lies the Sp1 binding domain (Jones et al. 1986), a functional TATA element, and binding regions downstream of the RNA initiation site for two positive-acting cellular proteins, LBP-1 and CTF/NF I (Jones et al. 1988; Wu et al. 1988). A role for LBP-1 as an activator of promoter function has been implicated by mutagenesis of the downstream region, and both LBP-1 and CTF/NF I sites partially overlap the Tat trans-activation domain (Jones et al. 1988). Detailed comparisons of binding to mutant HIV-1 promoters suggest that LBP-1 and CTF/ NF I might modulate the efficiency of trans-activation but that critical Tat activation sequences also lie between the binding domains of these two proteins. The role of the downstream region in promoter function and regulation is further complicated by observations that the HIV-1 Tat trans-activation target can form a stable RNA stem-loop structure in solution (Muesing et al. 1987), which appears from an analysis of compensatory point mutations to be required for the response to Tat (Feng and Holland 1988). Thus, the Tat-responsive regions of both HIV-1 and HIV-2 encompass DNA-binding sites for cellular proteins, as well as regions that specify extensive RNA secondary structure.

A relevant observation made during our previous studies was that HIV-1 transcription did not terminate in conventional in vitro transcription systems (Jones et al. 1988). In this paper we describe two distinct cell-free systems in which short RNAs are formed with $3^{\prime}$ ends that map within the $5^{\prime}$-untranslated leader regions of the HIV-1 and HIV-2 promoters. First, we demonstrate that RNA synthesis from the HIV-1 promoter is altered abruptly and efficiently when an active fractionated extract is exposed to sarkosyl, producing a series of short (58 to 61 nucleotides) HIV-1 RNAs that are similar in length to those detected in vivo in the absence of Tat or other transcriptional activators (Kao et al. 1987). RNA polymerase II transcription from the HIV-2 promoter demonstrates the same sensitivity in these extracts to sarkosyl treatment but generates a single, distinctly terminated transcript of 125-130 nucleotides, as detected by $3^{\prime}$ nuclease $\mathrm{Sl}$ analysis and runoff transcription experiments. Although highly variable in this response, nuclear extracts derived from HeLa cells can also demonstrate as high as $20 \%$ termination of HIV transcription in the absence of sarkosyl. Studies of the origin of the short HIV-2 RNAs in each transcription extract suggest that they are derived either from transcription termination or from a rapid cotranscriptional RNA processing step, rather than post-transcriptional RNA processing or topoisomerase-induced DNA cleavage events. In vitro transcription experiments with recombinant HIV-2 promoters reveal the existence of an orientationdependent element that acts in conjunction with one or more elements of the HIV promoter to specify the positioning of the $3^{\prime}$ ends of the short transcripts. Analysis of termination efficiency upon incorporation of two distinct ribonucleoside analogs indicates that RNA secondary structure formation may also be required. The systems described here provide direct evidence of a cellular process that generates truncated RNA polymerase II transcripts from the HIV promoters and further demonstrate the complexity of overlapping elements within the HIV promoter-proximal downstream region.

\section{Results}

Short HIV-1 RNA transcripts are detected in a fractionated transcription system treated with sarkosyl

In a previous study we noted that transcription from the HIV-1 promoter generated only fully elongated RNA molecules in vitro (Jones et al. 1988) rather than abbreviated 55- to 59-nucleotide transcripts similar to those detected in vivo in the absence of Tat (Kao et al. 1987). This apparent discrepancy between the in vivo and in vitro properties of the HIV-1 promoter raised the possi- 
bility that in vitro transcription extracts possess relatively high levels of cellular antiterminator proteins or other activities that counteract the function of proteins involved in the synthesis of short RNAs. Moreover, because short HIV RNAs can be detected in vivo in the absence of virus or viral proteins, all of the components required for termination should be present in extracts derived from uninfected cells. To dissect different stages of HIV transcription in vitro, we decided to analyze the response of the HIV promoters to sarkosyl, an anionic detergent that can affect differentially the initiation and elongation phases of transcription by RNA polymerase II (Green et al. 1975; Ackerman et al. 1983; Hawley and Roeder 1985, 1987; Cai and Luse 1987).

A HeLa whole-cell extract was fractionated by chromatography on heparin-agarose resin, and protein fractions eluting at $0.4 \mathrm{M} \mathrm{KCl}(\mathrm{H} .4)$ were dialyzed and used for in vitro transcription reactions. Preinitiation tran- scription complexes were assembled onto linear HIV-1 promoter templates, and initiation was allowed to proceed for $30 \mathrm{sec}$ prior to the addition of different concentrations of sarkosyl (Fig. 1A). Concentrations of sarkosyl $>0.015 \%$ abolish reinitation events but do not prevent elongation (Hawley and Roeder 1985), which was allowed to proceed for a $30-\mathrm{min}$ interval prior to resolution of runoff transcripts on denaturing polyacrylamide gels. As shown in Figure 1B, only full-length 470-nucleotide runoff transcripts were detected in the absence of sarkosyl or at low concentrations $(0.015 \%)$ of the detergent. Somewhat unexpectedly, the full-length HIV-1 transcript disappeared upon incubation of the extract with moderate levels of sarkosyl $(0.05-0.15 \%$; Fig. 1B, lanes 3-6) and then returned in the presence of higher levels of the detergent $(0.25-0.40 \%$; Fig. 1B, lanes 7,8$)$. The possibility that HIV-1 transcription terminated prematurely with moderate levels of sarkosyl could not be

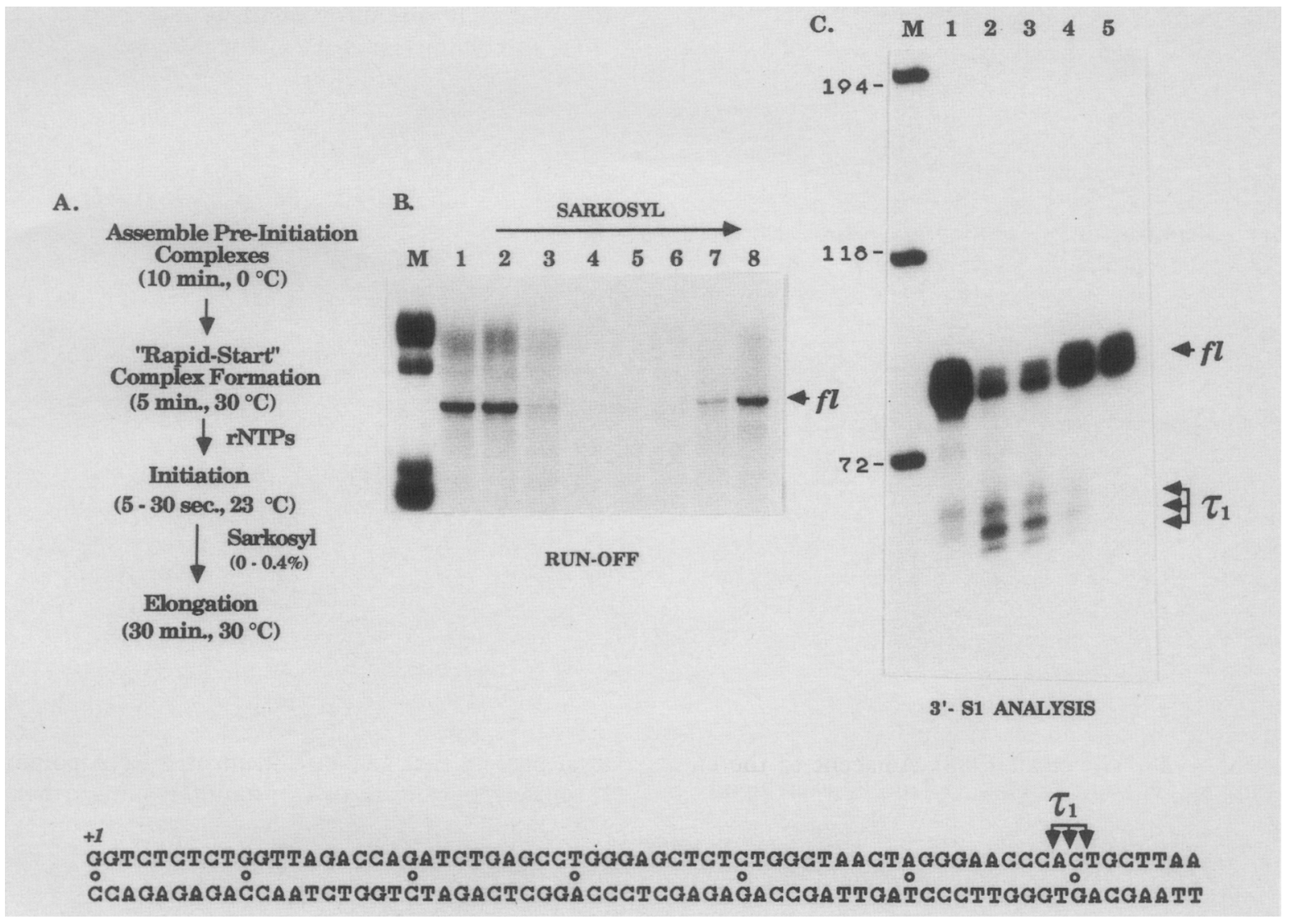

Figure 1. Effects of sarkosyl on HIV-1 transcription elongation efficiency in vitro. $(A)$ Outline of the in vitro transcription protocol carried out with a heparin-agarose $0.4 \mathrm{M} \mathrm{KCl}$ step fraction (H.4), supplemented with different amounts of the anionic detergent sarkosyl. (B) Detection of HIV-1 runoff transcripts in vitro at different sarkosyl concentrations. Each $50 \mu 1$ reaction contained $1.0 \mu \mathrm{g}$ of EcoRI-digested pLTR-1/CAT template and $100 \mu \mathrm{g} \mathrm{H.4} \mathrm{extract.} \mathrm{The} \mathrm{final} \mathrm{sarkosyl} \mathrm{concentration} \mathrm{in} \mathrm{each} \mathrm{reaction} \mathrm{was} 0.015 \%$ (lane 2), $0.05 \%$ (lane 3), $0.075 \%$ (lane 4), $0.10 \%$ (lane 5), $0.15 \%$ (lane 6 ), $0.25 \%$ (lane 7 ), and $0.40 \%$ (lane 8 ). (Lane 1) Reaction without added sarkosyl. Markers (M) are HaeIII-cleaved $\phi X 174$ DNA. (fl) Position of the 470-nucleotide full-length runoff transcript. (C) Detection of short HIV-1 RNA transcripts by nuclease S1 analysis. Transcription reactions contained $1.0 \mu \mathrm{g}$ EcoRI-digested pLTR-1/CAT $\Delta \mathrm{H}$ and $100 \mu \mathrm{g}$ of $\mathrm{H} .4$ extract supplemented with 0 (lane 1 ), $0.05 \%$ (lane 2 ), $0.10 \%$ (lane 3), $0.15 \%$ (lane 4 ), or $0.40 \%$ (lane 5 ) sarkosyl (wt/vol, final concentration). The $3^{\prime}$ end-labeled probe used for nuclease Sl analysis corresponded to positions -4 to +182 in the HIV-1 LTR. The 80-nucleotide full-length (fl) and the 58- to 61-nucleotide HIV-1 transcripts $\left(\tau_{1}\right)$ are indicated with arrows. Markers $(M)$ are as in $B$. (Bottom) Sequence of the HIV-l termination region. 
examined directly because radioactive contaminants from the labeled guanosine nucleotides obscured the lower regions of the gel in which RNA molecules shorter than 70 nucleotides would migrate. To test for short transcript formation in the presence of sarkosyl, RNA was analyzed with the nuclease S1 technique, using an end-labeled probe that allowed identification of the authentic $3^{\prime}$ ends of each RNA species (see Methods). The results revealed that the decreased levels of full-length transcripts observed in the presence of $0.05-0.15 \%$ sarkosyl were accompanied by the appearance of a heterogeneous collection of RNAs between 58 and 61 nucleotides in length (Fig. 1C, lanes 2,3), which strongly resemble the pattern of HIV-1 transcripts observed in transfection experiments without Tat (Kao et al. 1987|. Consistent with the data obtained by runoff experiments, the short HIV-l RNAs cease to be made and full-length transcripts once again predominate at high levels of sarkosyl (Fig. 1C, lanes 4,5). The $3^{\prime}$ ends of the short RNA molecules $\left(\tau_{1}\right)$ lie downstream of DNAbinding sites for transcription factors LBP-1 and CTF/NF I (Jones et al. 1988) and just beyond the $3^{\prime}$ border of the
Tat-responsive region at approximately +55 (Hauber and Cullen 1988; Jakobovitz et al. 1988).

\section{Sarkosyl induces a longer transcript of 130 nucleotides from the HIV-2 promoter}

If Tat functions to overcome termination, we re:asoned that short RNAs should also be detected in vitris from the HIV-2 promoter, which is regulated in vivo in a manner similar to HIV-1 (Emerman et al. 1987; Jakobovitz et al. 1988). To examine this possibility, transcripts from linear HIV-2 promoter templates were analyzed by runoff experiments in the H.4 extract supplemented with different amounts of sarkosyl. As seen previously with the HIV-1 promoter, only full-length 240 -nucleotide HIV-2 runoff transcripts were observed in the absence of detergent or at low levels of sarkosyl (Fig. 2A, lanes 1,2$\}$. Addition of moderate levels of sarkosyl $\{0.05-$ $0.15 \%$ ) produced a shorter HIV-2 RNA of $\sim 125$ nucleotides (Fig. 2A, lanes 3-6). The 125-nucleotide HIV-2 RNAs disappeared again at higher sarkosyl concentrations in conjunction with the reappearance of the full-

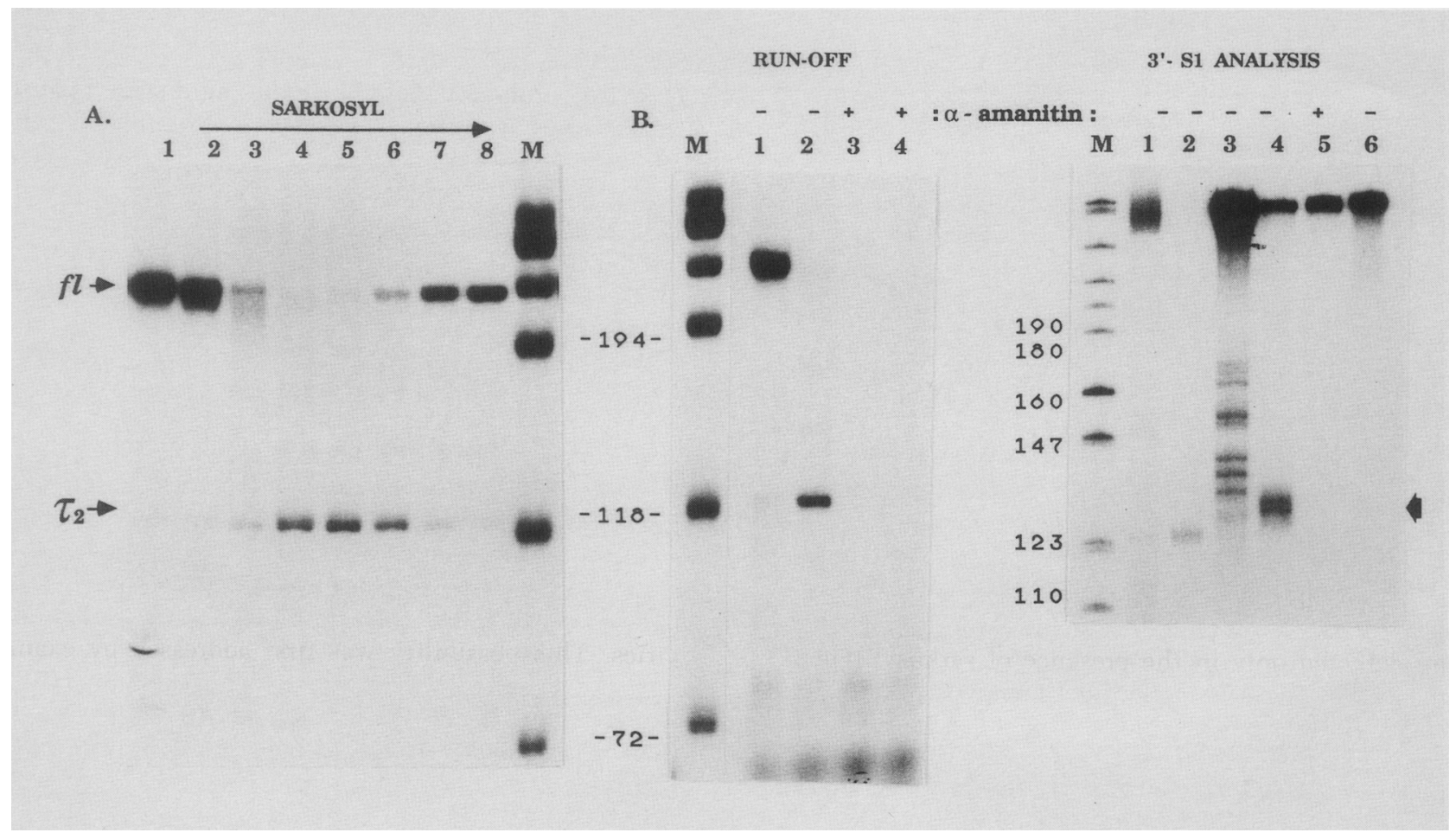

Figure 2. Effect of sarkosyl on transcription elongation efficiency at the HIV-2 promoter. (A) Detection of HIV-2 prematurely terminated transcripts in runoff experiments. Reactions contained $500 \mathrm{ng}$ EcoRI-cleaved pLAV2C and $100 \mu \mathrm{Hg} .4$ extract incubated alone (lane 1 ) or with sarkosyl at $0.015 \%$ (lane 2), $0.05 \%$ (lane 3), $0.075 \%$ (lane 4$), 0.10 \%$ (lane 5$), 0.15 \%($ lane 6$), 0.25 \%($ lane 7$)$, or $0.40 \%$ (lane 8 ). The positions of the 240 -nucleotide full-length runoff (fl) and the 130 -nucleotide terminated $\left(\tau_{2}\right)$ HIV-2 transcripts are indicated with arrows. Markers $(M)$ are HaeIII-cleaved $\phi X 174$ DNA. $(B)$ Runoff transcription reactions were prepared as described above and contained 0 (lanes 1,3 ) or $0.10 \%$ sarkosyl (lanes 2,4) without $\alpha$-amanitin (lanes 1,2), or with $2.0 \mu \mathrm{g} / \mathrm{ml} \alpha$-amanitin (lanes 3,4). (Lanes 1,2) Runoff transcript analysis in the absence and presence of $0.10 \%$ sarkosyl, respectively. Markers $(M)$ are HaeIII-cleaved $\pi \mathrm{X} 174$ DNA. Transcription reactions for 3'-S1 nuclease analysis contained $500 \mathrm{ng}$ EcoRI-cut pLAV2C without sarkosyl (lane 3) or with $0.10 \%$ sarkosyl (lanes 4). The reaction shown in lane 5 was identical to that of lane 4 , except that $\alpha$-amanitin was added to a final concentration of $2.0 \mu \mathrm{g} / \mathrm{ml}$. A control nuclease S1 digestion containing $30 \mu \mathrm{g}$ yeast RNA is shown (lane 6). Markers $(M)$ are $M s p I-d i-$ gested pBR322 DNA. 
length 240-nucleotide RNA species (Fig. 2A, lanes 7,8). Synthesis of both the 240-nucleotide (fl) and 125-nucleotide $\left(\tau_{2}\right)$ HIV-2 RNAs was inhibited completely by low levels of $\alpha$-amanitin $(2 \mu \mathrm{g} / \mathrm{ml}$; Fig. 2B, cf. lanes 1,2 with lanes 3,4 ), indicating that both are authentic RNA polymerase II transcripts.

The short HIV-2 RNA $\left|\tau_{2}\right|$ was detected also with an end-labeled probe that maps the authentic $3^{\prime}$ end to nucleotide +130 by nuclease S1 digestion (Fig. 2B, lane 4 , right). The small discrepancy in the migration position of the runoff transcript and the nuclease S1 duplex product (Fig. 2B, cf. lanes 2 and 4 ) is due to the differential migration of RNA and DNA on denaturing gels. Because of this discrepancy, we can only map the size of the short RNA with precision to between 125 and 130 nucleotides in length, and for simplicity we will henceforth refer to the size of $\tau_{2}$ as 130 nucleotides. Thus, termination downstream of the HIV-2 promoter resembles that seen with the HIV-1 promoter in that either fulllength or short transcripts predominate, depending on the exact levels of sarkosyl in the extract. One distinction between the HIV promoters was that a longer RNA was produced from the HIV-2 promoter in response to sarkosyl, which could be detected directly in runoff experiments. In addition, HIV-2 RNA transcripts were more precisely positioned than the heterogeneous HIV-1 transcripts. We conclude that $3^{\prime}$ end formation is sequence dependent in that it varies in accuracy and positioning between RNAs transcribed from the HIV-1 and HIV-2 promoters.

\section{Differential response of HIV promoter and AdMLP to sarkosyl}

Sarkosyl-dependent effects of elongation efficiency in vitro have been observed previously with the AdMLP (Hawley and Roeder 1985), which is thought to pause or terminate prematurely in adenovirus-infected cells (Mok et al. 1984). The responses of the AdMLP and HIV-2 promoter to different levels of sarkosyl were compared directly with runoff experiments (Fig. 3). As observed previously by Hawley and Roeder (1985), 186-nucleotide adenovirus RNA transcripts $\left(\tau_{\mathrm{Ad}}\right)$ that are substantially shorter than the 540-nucleotide runoff RNAs were detected only in the presence of sarkosyl (Fig. 3, lanes 4-6). The 186-nucleotide adenovirus RNA persisted at high sarkosyl concentrations $(0.40 \%)$ that prevented HIV termination and restored full-length HIV-2 transcripts. Furthermore, the relative amounts of fulllength and short adenovirus RNAs did not change in response to variations in sarkosyl levels. Thus, the efficient switch between full-length and terminated transcripts seen with the HIV promoters at both transitions of the sarkosyl titration curve was not evident with transcripts originating from the adenovirus promoter. One interpretation of these data is that a cellular factor acts to prevent HIV termination in untreated H.4 extracts and is preferentially dissociated from the transcription complex by moderate levels of sarkosyl. A similar factor may operate in a less efficient manner at the

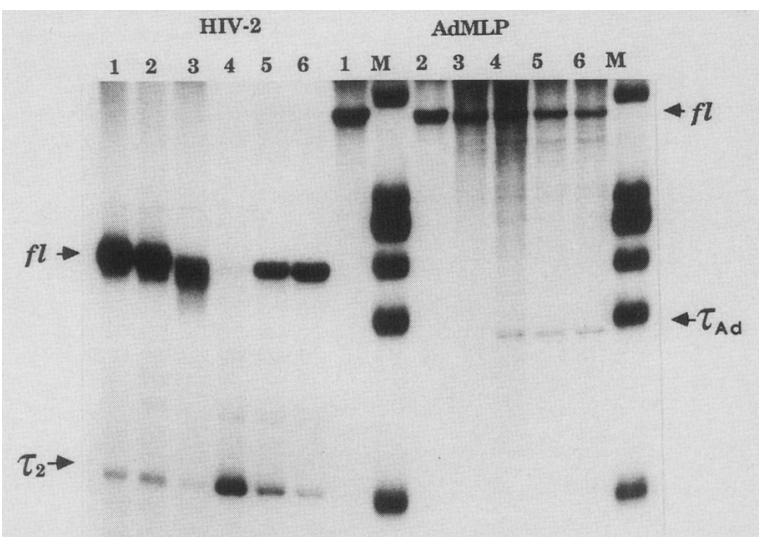

Figure 3. Differential effects of sarkosyl on transcription from the HIV-2 promoter and AdMLP. Runoff transcription reactions contained $100 \mu \mathrm{g} \mathrm{H} .4$ extract and either $500 \mathrm{ng}$ EcoRI-cleaved pLAV2C (HIV-2) or $1.0 \mu \mathrm{g} \mathrm{BamHI-cleaved} \mathrm{pLAX} \mathrm{(AdMLP),} \mathrm{as}$ indicated, either alone (lane 1) or supplemented with sarkosyl to a final concentration of $0.015 \%$ (lane 2), $0.05 \%$ (lane 3), $0.10 \%$ (lane 4 ), $0.25 \%$ (lane 5 ), or $0.40 \%$ (lanes 6 ). The positions of the 240-nucleotide HIV-2 and 540-nucleotide adenovinus runoff transcripts (fl) and the 130-nucleotide HIV-2 $\left(\tau_{2}\right)$ and 186nucleotide adenovirus $\left(\tau_{\text {Ad }}\right)$ short transcripts are indicated with arrows. Markers $(M)$ are HaeIII-cleaved $\phi X 174$ DNA.

adenovirus promoter, possibly inducing a strong pause that does not result in complete termination of transcription. The differential response of the two promoters to high sarkosyl concentrations argues that HIV termination requires a component that does not operate on the adenovirus promoter, such as a distinct factor or a nucleic acid structure that is inactivated at very high sarkosyl concentrations.

\section{Evidence that $3^{\prime}$ end formation of the short RNA molecules may involve cotranscriptional RNA processing}

Although the short HIV RNAs are thought to represent prematurely terminated transcripts, the possibility exists that they actually arise by distinct cellular events that involve RNA processing or DNA topoisomerase activities. This possibility was first addressed by examining the kinetics of appearance of the short HIV-2 RNAs in the presence of $0.1 \%$ sarkosyl (Fig. 4). Interestingly, the initial RNA transcripts formed under these conditions were longer than the 130-nucleotide $\tau_{2}$ RNA (lanes 2-4). Transcripts elongated slowly to full-length size within a 10-min incubation period (lane 3), at which time only a small amount of the short RNA was detectable. The short RNAs accumulated within 20-30 min (lanes 4,5), accompanied by a corresponding decrease in the amount of full-length transcripts. Because transcript reinitiation is inhibited in the presence of $0.1 \%$ sarkosyl, each of the RNAs monitored in lanes $2-5$ were derived from a single round of transcription. To evaluate further the possibly that an RNA processing step might create the $3^{\prime}$ ends of the short RNAs, we examined the 


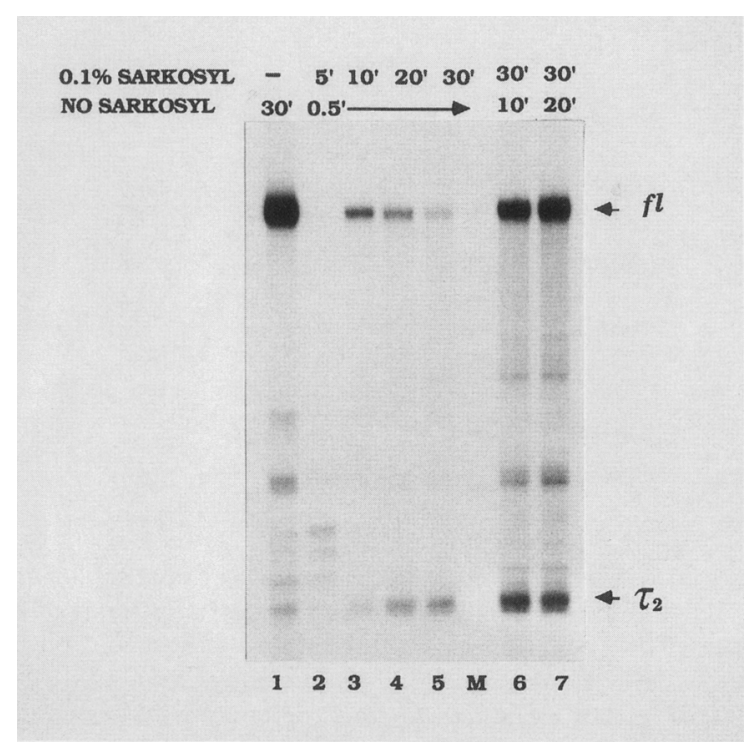

Figure 4. Short HIV RNAs may derive from a cellular RNA processing activity induced by sarkosyl. Following transcription initiation, sarkosyl was added to $0.10 \%$, and the reactions further incubated for either 5 (lane 2), 10 (lane 3), 20 (lane 4), or 30 (lane 5 ) $\mathrm{min}$ before being stopped. Alternatively, the reactions were initiated and allowed to elongate for either 10 (lane 6) or 20 (lane 7) min before the addition of sarkosyl to $0.10 \%$, after which they were incubated for an additional $30 \mathrm{~min}$. (Lane 1) Reaction did not contain sarkosyl and was allowed to proceed for $30 \mathrm{~min}$. Lane $M$ contains DNA markers. The differences in intensity between the transcripts seen in lanes 2-5 and those in lanes 1,6 , and 7 reflect the inhibition of transcript reinitiation by sarkosyl.

effect of adding sarkosyl at delayed time points, which allowed RNA synthesis to proceed beyond initiation into the elongation phase. If sarkosyl was added within 10-20 min after initiation, both full-length and short RNAs were generated in approximately equal amounts (Fig. 4, lanes 6,7). These small RNAs were not detected at equivalent time points in the absence of sarkosyl (data not shown). Although the data suggest that the $3^{\prime}$ end of the short RNA may be formed by an RNA processing activity, we cannot rule out the possibility that two unrelated processes are occurring in this extract, one that permits the slow elongation of the terminated RNA only in the presence of sarkosyl and another that degrades full-length RNA with similar kinetics.

To test for post-transcriptional RNA processing activity in the H.4 extract, labeled full-length HIV-2 RNA was isolated from in vitro transcription reactions and reincubated in the H.4 extract in either the presence or absence of sarkosyl. Incubation without added detergent resulted in partial degradation of the 240-nucleotide HIV-2 RNA (Fig. 4A, cf. lanes 1 and 2), whereas the same RNA was completely protected from nuclease digestion by moderate levels of sarkosyl $(0.10 \%$; lane 3$)$. There was no evidence of the 130-nucleotide RNA in either incubation reaction, indicating that the short HIV-2 transcripts are not generated post-transcriptionally by RNA processing or degradation activities present in the H.4 extract. Incubation of a full-length HIV-1 transcript in the H.4 extract in the absence of sarkosyl did not completely degrade the RNA but, instead, generated a single nuclease-resistant HIV-1 RNA species that most likely includes the stable HIV-1 hairpin structure (data not shown). Addition of moderate levels of sarkosyl completely inactivated this nuclease activity, however, and only full-length RNAs identical to the input HIV-1 RNA were observed. Thus, the short HIV-1 and HIV-2 RNAs, which are detected in transcription reactions only in the presence of moderate levels of sarkosyl, cannot be generated by post-transcriptional RNA processing events. If RNA processing is the mechanism of 3 '-end formation of the short HIV RNAs, this step appears to be closely coupled to RNA synthesis.

Further analysis of the H.4 extract revealed that labeled DNA fragments containing the HIV initiation site and downstream sequences were completely stable when incubated in either the presence or absence of sarkosyl (Fig. 5B). These data remove the possibility that DNA topoisomerase activities induced in the H.4 extract by sarkosyl had cleaved or nicked the HIV-2 template specifically at a position that would generate a 130-nucleotide RNA runoff transcript. To determine whether the size of the short RNAs was influenced by the position of truncation of the promoter template, transcripts from supercoiled HIV-2 promoters were examined in runoff experiments. As shown in Figure 5C (lanes 2,4), transcription from circular molecules generated a 130-nucleotide HIV-2 RNA species that comigrates with the short RNA produced from linear DNA templates. These observations are consistent with either premature termination or rapid cotranscriptional processing mechanisms.

\section{Interaction of LBP-1 and CTF/NF I with HIV-2 downstream sequences}

To evaluate the potential influence of cellular DNAbinding proteins on the synthesis of the short RNAs, it was important to analyze the proteins bound to the downstream regions of the HIV-2 template in vitro. Although we have shown that the HIV-2 promoter-proximal downstream sequences interact with both CTF and LBP-1 transcription factors (Jones et al. 1988), the termination site identified here lies considerably downstream of the area examined previously. To determine whether binding sites for these cellular transcription factors extend within the termination region, DNase I footprint experiments were carried out with affinity-purified fractions of LBP-1 (M. Schorpp, M. Waterman, and K.A. Jones, unpubl.) and CTF/NF I (Jones et al. 1986). The results reveal that the strong LBP-1 binding domain described previously $(+34$ to +80$)$ lies immediately adjacent to a second, somewhat weaker LBP-1 binding region that extends downstream to approximately +125 (Fig. 5D). Thus, the complete LBP-1 domain on the HIV-2 promoter spans a striking 90 -bp region down- 


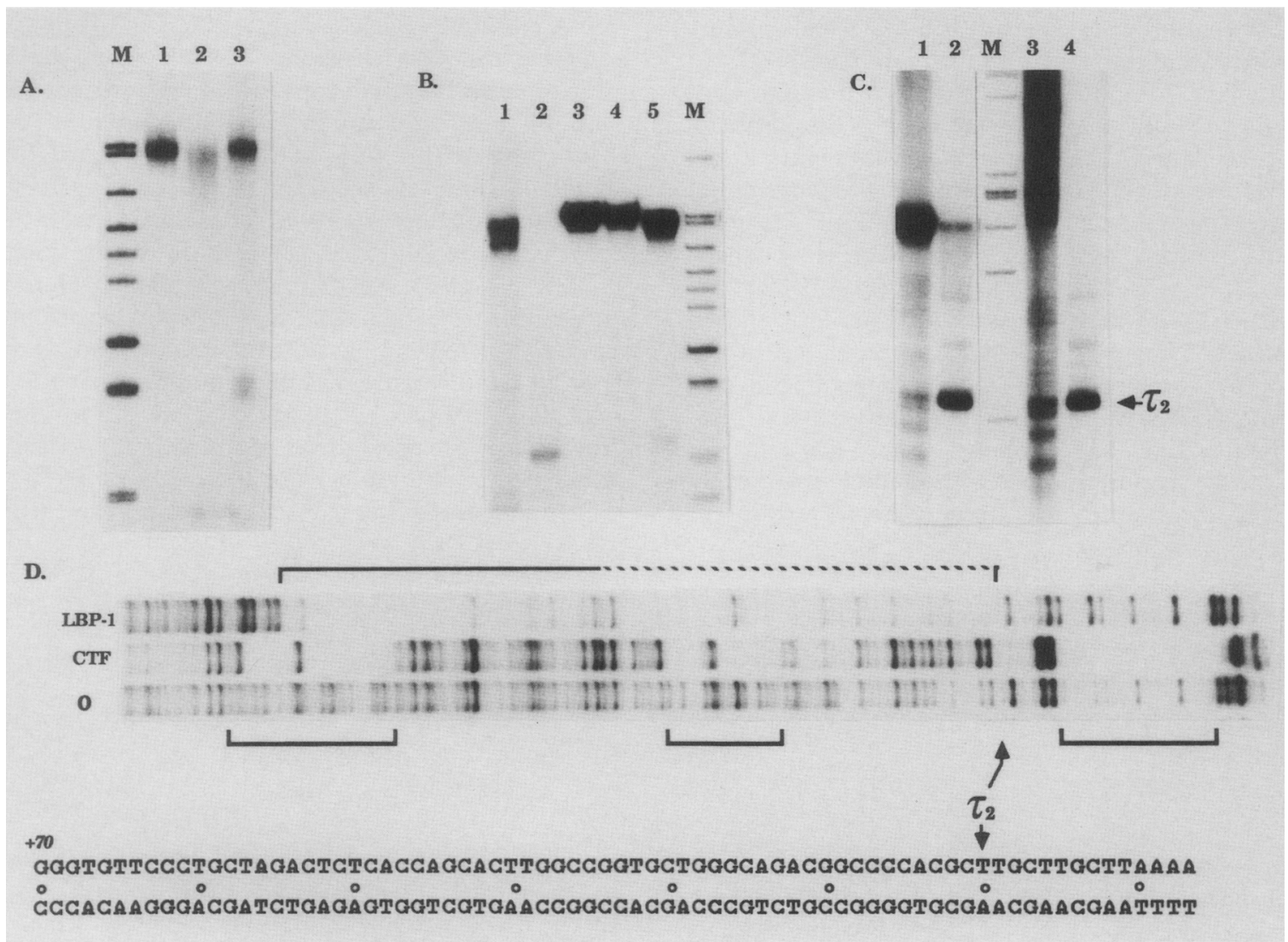

Figure 5. $(A)$ The short HIV-2 RNAs are not derived by post-transcriptional RNA-processing events. Full-length, appropriately initiated and capped HIV-2 runoff transcripts were derived by in vitro transcription of EcoRI-cleaved pLAV2C in H.4 extract without the addition of sarkosyl. HIV-2 RNA was isolated and incubated in either TM containing $0.1 \mathrm{M} \mathrm{KCl}$ (lane 1 ) or $100 \mu \mathrm{g} \mathrm{H.4} \mathrm{extract} \mathrm{in} \mathrm{the}$ absence of sarkosyl (lane 2) or in the presence of $0.10 \%$ sarkosyl (lane 3). (B) The short HIV-2 RNAs are not generated by topoisomerase nicking of the DNA template. Labeled DNA fragments containing HIV-2 downstream sequences (positions -4 to +175 ) were incubated with TM containing $0.1 \mathrm{M} \mathrm{KCl}$ (lane 3), $100 \mu \mathrm{g}$ of $\mathrm{H.4}$ extract without added sarkosyl (lane 4), or $\mathrm{H.4}$ extract with $0.10 \%$ sarkosyl (lane 5). Also shown are the runoff transcripts generated by transcription of $500 \mathrm{ng}$ EcoRI-cleaved pLAV2C incubated with $100 \mu \mathrm{g} \mathrm{H.4}$ extract in either the absence (lane 1) or presence (lane 2) of $0.10 \%$ sarkosyl. $(C)$ The size of the short HIV-2 transcripts is not influenced by the position of DNA truncation. In vitro transcription experiments were carried out with $500 \mathrm{ng}$ of pLAV2C, digested at the EcoRI site (lanes 1,2) or with supercoiled DNA templates (lanes 3,4) in the H.4 extract, either alone (lanes 1,3) or in the presence of $0.10 \%$ sarkosyl (lanes 2,4$)$. $(A-C)$ Products of the reactions after denaturing polyacrylamide gel electrophoresis and autoradiography. Markers $(M)$ are MspI-digested pBR322 DNA. $(D)$ Cellular proteins CTF and LBP-1 bind to the DNA sequences immediately upstream of the HIV-2 termination site. DNase I footprinting experiments were carried out as described by Jones et al. (1988), using HIV-2 DNA fragments labeled $\sim 190$ nucleotide downstream from the RNA start. The probe was incubated in the absence of protein (0) or in the presence of $30 \mathrm{ng}$ each of affinity-purified CTF or LBP-1 fractions, as indicated. Regions protected from digestion by CTF are indicated by brackets, whereas the LBP-1 binding region is indicated above, subdivided by relatively high- (solid line) and low-(dashed line) affinity domains. (Bottom) Sequence of the HIV-2 downstream region; the approximate location of the termination site $\left(\tau_{2}\right)$ is indicated with an arrow.

stream of the HIV-2 promoter. Two additional binding regions for CTF/NF I were also uncovered, including a low-affinity site that overlaps the LBP-1 binding region and a stronger site that lies just beyond the region of termination. No distinct DNA-binding activities were detected in DNase I footprint experiments carried out with $10-20 \mu \mathrm{g}$ of the H.4 extract, and all DNA-binding interactions were effectively inhibited at moderate levels of sarkosyl $(0.10 \%$; data not shown). The position of the $3^{\prime}$ end of the short HIV-2 RNA $\left(\tau_{2}\right)$ relative to these binding interactions is indicated at the bottom of Figure 5.

\section{Positioning of short RNA transcripts requires HIV} leader sequences

The different lengths of short RNA transcripts from the HIV-1 and HIV-2 promoters strongly suggest that the positioning of the $3^{\prime}$ end is specified by sequences downstream of each promoter. Moreover, termination sites for both the HIV-1 and HIV-2 promoters lie adjacent to cellular DNA-binding protein domains, as well as at the end of potential RNA stem-loop structures in the HIV 5 -untranslated leader regions (see Fig. 8A). As an initial step toward identifying sequences that specify the strong 
HIV-2 termination site, a series of $3^{\prime}$ deletion mutants was generated and analyzed for termination efficiency in the H.4 extract. As shown in Figure 6A, full-length transcripts were readily detected from each of the deletion mutants, indicating that sequences downstream of +34 are not required for initiation from the HIV-2 promoter. Moreover, transcription from pHIV-2/CAT plasmids containing downstream sequences to either position +175 or +125 terminated efficiently in the H. 4 extract supplemented with $0.10 \%$ sarkosyl. Thus, termination is not influenced by sequences at or immediately downstream of the $3^{\prime}$ ends of the short transcripts. In contrast, terminated RNA was not detected with mutants deleted to positions $+106,+101$, $+98,+85$, or +34 (Fig. $6 \mathrm{~A}$; other data not shown). In longer autoradiographic exposures, a very small amount of heterogeneous terminated
RNA could be detected from mutant +101 (Fig. 6B), indicating that downstream sequences might act to position the terminated transcripts. Heterogeneous transcripts were not apparent with the other deletion mutants, and neither full-length nor short transcripts were detected from any of these deletion templates in the presence of $0.10 \%$ sarkosyl. These data suggest that sequences specifying the positioning of termination are contained, in whole or in part, within promoter-proximal downstream sequences between positions +125 and +101 . This downstream region overlaps with a portion of the downstream LBP-1 binding site on DNA and also corresponds with a putative RNA stem-loop structure that is the most distal of three such structures from the HIV-2 promoter (see Fig. 8A).

We also noted that transcription from the entire series

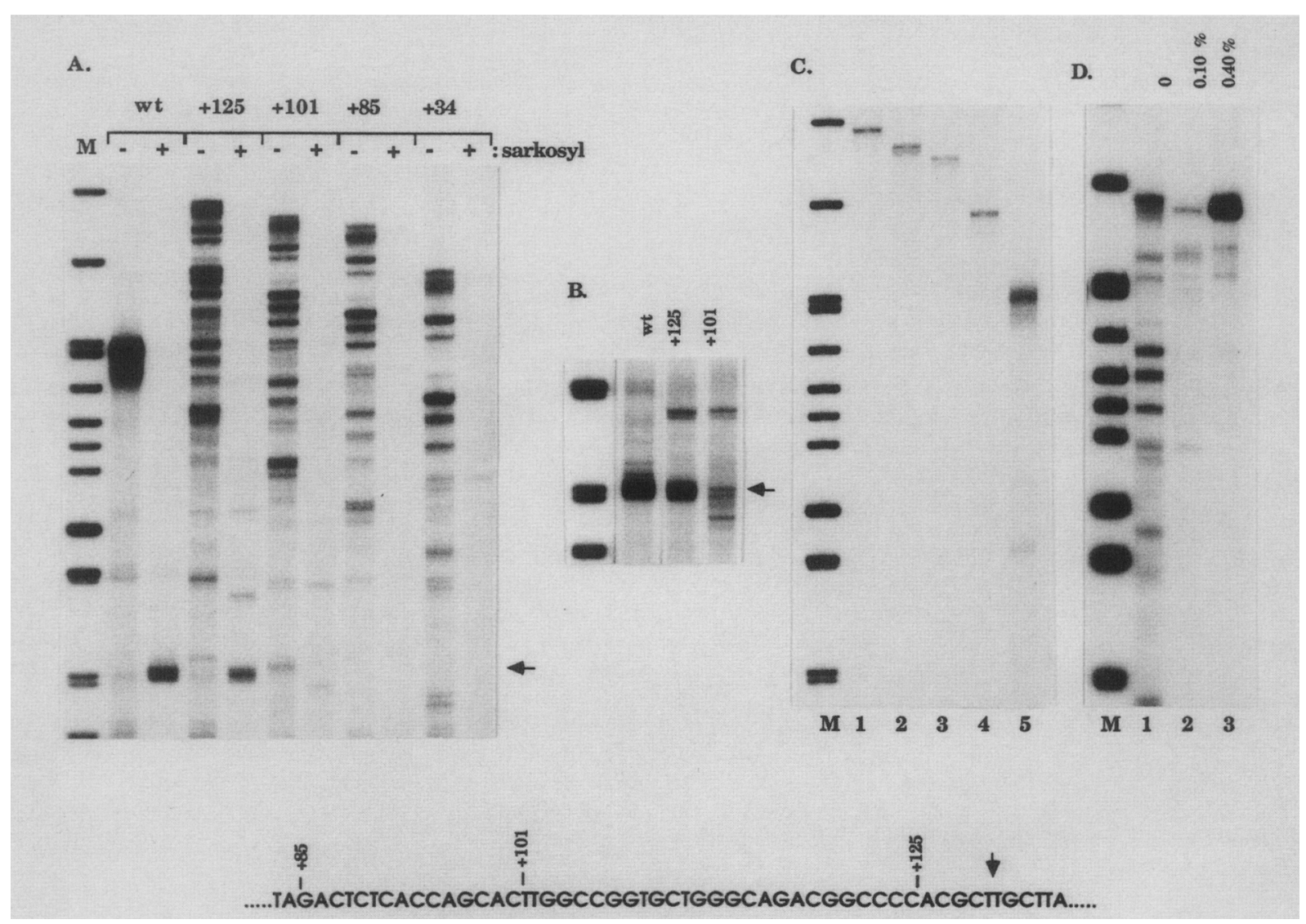

Figure 6. $(A)$ Downstream HIV-2 sequences are required for appropriate termination in vitro. Different HIV-2 deletion mutant plasmids $(500 \mathrm{ng}$, top) were linearized with EcoRI and incubated with $100 \mu \mathrm{g} \mathrm{H.4}$ extract alone or in the presence of $0.10 \%$ sarkosyl, as indicated above each lane. The position of the 130-nucleotide prematurely terminated transcript is indicated by the arrow. $(B)$ Sideby-side comparison of terminated transcripts from mutants +125 and +101 , aligned from the appropriate locations of the autoradiogram in $A$. A longer autoradiographic exposure is shown in $B$, relative to $A$, to demonstrate the heterogeneity of short transcripts detected with mutant +101 . The position of the 130-nucleotide HIV-2 transcript is indicated by the arrow. $(C)$ An H.4 extract containing high levels of cellular antiterminator activity generates full-length transcripts from the HIV-2 $3^{\prime}$-deletion mutant templates. Transcription reactions were carried out as described for $A$, except a different H.4 extract was used. The HIV-2 $3^{\prime}$-deletion mutants $+125,+101,+98,+85$, and +34 were used in reactions shown in lanes $1-5$, respectively. The autoradiogram was obtained with a twofold shorter autoradiographic exposure time than that in $A$. (D) Sarkosyl-induced transitions in elongation efficiency are specified by HIV-2 promoter sequences upstream of position +34 . Transcription reactions were performed containing $500 \mathrm{ng}$ of the $3^{\prime}$-deletion mutant pHIV-2/CAT +34 , linearized with EcoRI, and $100 \mu \mathrm{g} \mathrm{H.4} \mathrm{extract} \mathrm{alone} \mathrm{(lane} \mathrm{1),} \mathrm{or} \mathrm{with} \mathrm{either} 0.10 \%$ sarkosyl (lane 2) or $0.40 \%$ sarkosyl (lane 3). Size markers $(M)$ are $M$ spI-digested pBR322 DNA. (Bottom) Deletion mutant endpoints relative to the approximate termination site (arrow) are indicated in the HIV-2 sequence diagram. 
of pHIV-2/CAT plasmids was elongated inefficiently in the H.4 extract in the absence of sarkosyl, creating a series of distinct sized transcripts smaller than the fulllength transcript but larger than the +130 -nucleotide terminated transcript (Fig. 6A). This pattern of inefficiently elongated transcripts was not detected with wild-type HIV-2 promoter plasmids that lack the chloramphenicol acetyltransferase (CAT) gene (Fig. 6A, wt) and therefore may arise from pausing at sequences within the CAT gene itself. Thus, although the untreated H.4 extract contained relatively high levels of factors that accentuate pausing or low levels of proteins that contribute to the processivity of RNA polymerase II, the specific HIV-2 termination site was nevertheless recognized only in the presence of sarkosyl. In contrast, transcripts from the pHIV-2/CAT deletion templates were elongated efficiently in a different transcription extract that contains high levels of cellular antitermination activities (Fig. 6C). Furthermore, the latter extract was unable to recognize the HIV-2 termination signal at moderate levels of sarkosyl (data not shown). Although a more precise understanding of the differences between these two types of transcription extracts requires further investigation, we interpret these data to suggest that sarkosyl treatment permits the efficient recognition of HIV-2 termination signals only in those extracts that contain high levels of pausing or termination factors, low levels of cellular antiterminator activities, or both.

Formation of short HIV RNAs may require compatible elements in the promoter

Somewhat unexpectedly, deletions of the downstream HIV-2 region that prevent the appearance of the $\tau_{2}$ RNA do not restore full-length transcription simultaneously to wild-type levels. This is not due to impaired promoter activity caused by the removal of downstream sequences, because full-length runoff transcripts were readily detected from these same mutants in the absence of sarkosyl (Fig. 6A,C). This result is particularly intriguing in light of observations that removal of downstream sequences does not restore wild-type promoter function in vivo from either the HIV-1 or HIV-2 promoters (Rosen et al. 1985; Cullen 1986; Peterlin et al. 1986; Jakobovitz et al. 1988). One explanation is that the downstream sequences act primarily to localize the terminated transcripts rather than cause termination directly. Thus, transcripts apparently continue to terminate or be processed, albeit randomly or at cryptic and undetectable termination signals, in the absence of HIV-2 downstream sequences. These observations led us to ask whether the restoration of full-length transcripts seen at high sarkosyl levels depends on downstream sequences, as would be expected if high detergent concentrations had melted out a critical RNA structure or prevented the interaction of a nucleic acid-binding protein to the downstream termination region. As shown in Figure $6 \mathrm{D}$, addition of high levels of sarkosyl $(0.4 \%)$ restores full-length transcription from deletion mutant template pHIV-2/CAT +34 as efficiently as had been observed with the wild-type pHIV-2/CAT promoter. Moreover, the extensive pausing seen in the absence of sarkosyl (Fig. 6A) was no longer evident at high sarkosyl concentrations, and only fully elongated RNAs were detected. Thus, the reappearance of the full-length RNA species at high sarkosyl concentrations does not require sequences distal to the promoter and therefore cannot arise from differential protein interaction with downstream DNA or RNA sequences or from a melting out of RNA secondary structure. We conclude that although the HIV-2 downstream region is required in order to detect the terminated transcript, the break in full-length RNA synthesis seen at both edges of the sarkosyl titration curve is specified by the promoter and not by the downstream region.

Detection and pulse-chase analysis of the short HIV-2 RNAs in a nuclear transcription extract

The variability of termination efficiency among different extracts encouraged us to examine a variety of different crude extracts to determine whether short HIV RNAs could ever be detected without sarkosyl treatment. Of seven different extracts examined for HIV-2 termination in runoff experiments, only two were found to possess detectable levels of the 130-nucleotide RNA without sarkosyl treatment (Fig. 7A). We estimate that the highest termination efficiency of these nuclear extracts was $20 \%$ (based on the relative number of uridine residues in each RNA species), which is considerably less than that of the sarkosyl-treated H.4 extract. The 130-nucleotide RNA species generated with the nuclear extract was sensitive to low levels of $\alpha$-amanitin, could be readily detected from either supercoiled or linear templates (Fig. 7A), and required sequences downstream of the HIV-2 promoter (Fig. $7 \mathrm{~B}$ ) in a manner identical to the 130-nucleotide RNA induced by sarkosyl in the H.4 extract. These data indicate that termination downstream of the HIV promoters is not always dependent upon the addition of detergent, but rather is determined for each extract by the relative activities of cellular proteins involved in forming the short RNAs. The ability to detect the 130-nucleotide HIV-2 transcript in the absence of sarkosyl afforded the opportunity to evaluate the contributions of RNA degradation or pausing in this system with pulse-chase experiments (Fig. 7C). In these experiments, in vitro transcripts were labeled for $45 \mathrm{sec}$ prior to addition of an excess of unlabeled nucleotides. Whereas the 130-nucleotide HIV-2 RNA was readily detected following a 30-sec chase, the full-length 240-nucleotide runoff transcripts only appeared after a longer 1-min chase. The 130-nucleotide RNA was highly stable and did not extend into larger transcripts upon incubation periods as long as $15-30 \mathrm{~min}$ (Fig. $7 \mathrm{C}_{i}$ other data not shown). Thus, the 130-nucleotide RNA was synthesized rapidly in this extract and did not become incorporated into longer transcripts under these transcription conditions. If cotranscriptional RNA processing is required for the formation of short RNAs in this extract, it must occur rapidly relative to the process measured in the sarkosyl-treated extract. These data provide strong 


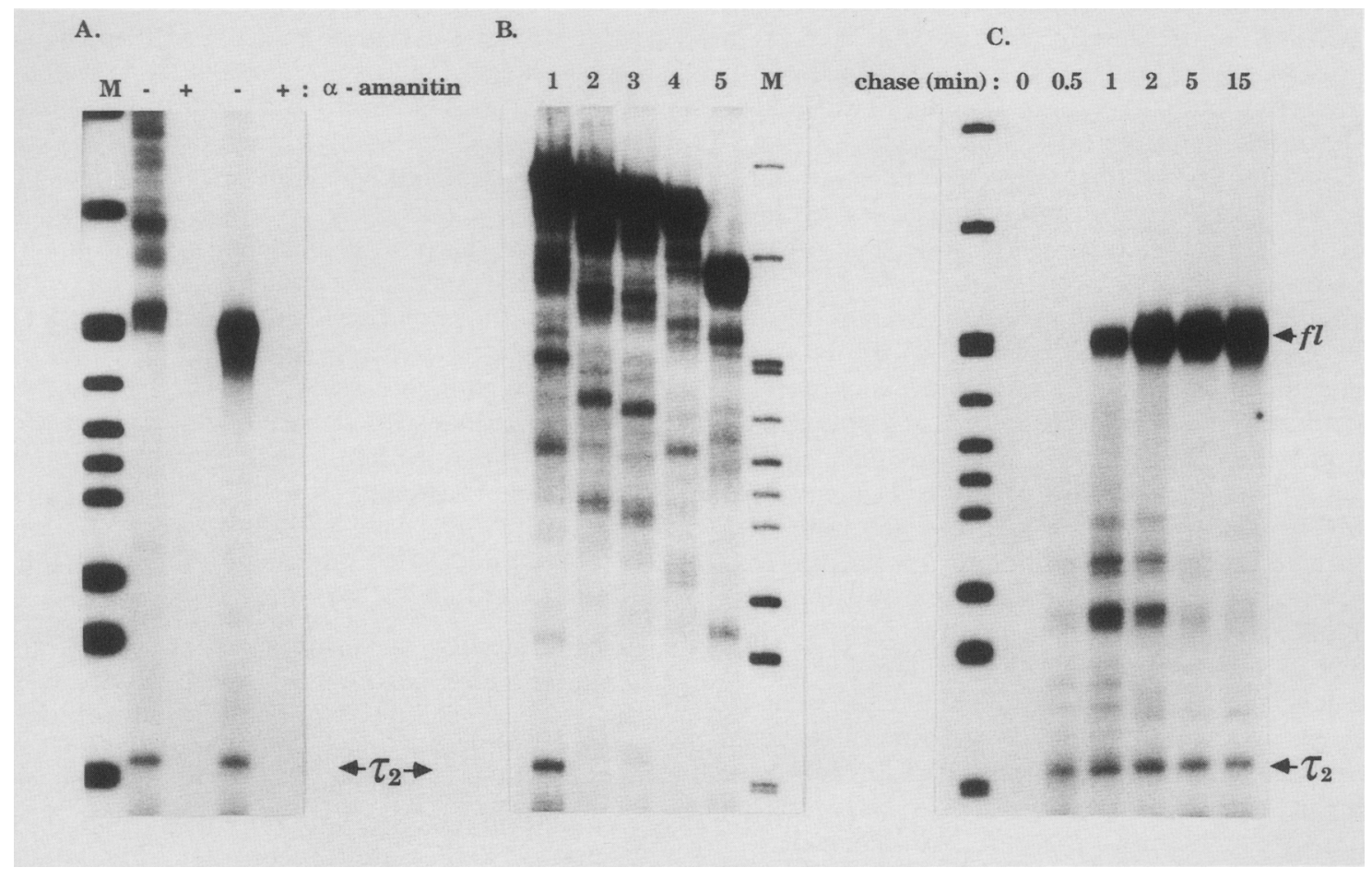

Figure 7. (A) HIV-2 transcription terminates with low efficiency in a HeLa nuclear extract in the absence of sarkosyl. Either supercoiled (lanes 1,2) or EcoRI-digested pLAV2C (lanes 3,4) was transcribed in $100 \mu \mathrm{g}$ of HeLa cell nuclear extract alone (lanes 1,3 ) or in the presence of $2.0 \mu \mathrm{g} / \mathrm{ml} \alpha$-amanitin (lanes 2,4). The position of the 130-nucleotide terminated HIV-2 transcript $\left(\tau_{2}\right)$ is indicated. $(B) \mathrm{HIV}-2$ downstream sequences are required for termination in the nuclear extract. Transcription reactions contained HIV-2 $3^{\prime}$-deletion mutant templates $+125,+101,+98,+85$, or +34 (lanes $1-5$, respectively), linearized with EcoRI. (C) Pulse-chase analysis of in vitro runoff transcripts. Reactions containing $500 \mathrm{ng}$ of EcoRI-digested pLAV2C and $100 \mu \mathrm{g}$ of HeLa nuclear extract were preincubated 15 min at $30^{\circ} \mathrm{C}$, and nucleotides were added to the reaction to final concentrations of $30 \mu \mathrm{M}$ each of ATP, GTP, and CTP and $1.3 \mu \mathrm{M}$ $\left[\alpha{ }^{32} \mathrm{P}\right] \mathrm{UTP}(600 \mathrm{Ci} / \mathrm{mmole})$. Following an incubation interval of $45 \mathrm{sec}$ at $30^{\circ} \mathrm{C}$, the concentration of each nucleotide was increased to $1.0 \mathrm{mM}$, and reactions were then stopped at various time intervals. Chase nucleotides were added simultaneously with the stop mix in the reaction shown in lane 1. The other reactions proceeded for $30 \mathrm{sec}$ (lane 2), $1 \mathrm{~min}$ (lane 3), $2 \mathrm{~min}$ (lane 4), $5 \mathrm{~min}$ (lane 5), or 15 min (lane 6). The position of the terminated $\left(\tau_{2}\right)$ and runoff $(\mathrm{fl})$ transcripts are indicated with arrows. Size markers $(M)$ are $M s p I-d i g e s t e d$ pBR322 DNA.

evidence that the 130-nucleotide RNA transcript arises from a termination event occurring downstream of the HIV-2 promoter.

RNA secondary structure formation may also be required to detect short transcripts in vitro

Because the HIV-2 termination region overlaps both LBP-1 binding sites on DNA and the third HIV-2 RNA hairpin structure (Fig. 8A), it was important to evaluate the relative contributions of DNA and RNA signals to termination in vitro. Several observations argued against a role for LBP-1 in inducing termination at the HIV-2 promoter. For example, both the nuclear and H.4 transcription extracts in which termination could be detected generally contained low amounts of DNAbinding proteins, and addition of high levels of purified LBP-1 stimulated overall transcription but did not alter the relative ratios of terminated and full-length RNAs (data not shown). In addition, termination efficiency in the H.4 extract was relatively insensitive to overall DNA template levels, which could be varied from 1 $\mu \mathrm{g} / \mathrm{ml}$ to $20 \mu \mathrm{g} / \mathrm{ml}$ without influencing the relative termination efficiency. Finally, termination in the H.4 extract was detected in the presence of sarkosyl concentrations that completely inhibited the DNA-binding activities present in the H.4 extract in DNase I footprint experiments. Thus, the prevailing evidence suggests that downstream DNA-binding proteins such as LBP-1 do not mediate termination of HIV-2 transcription and indicate a role for RNA sequence or structure in this process.

To investigate the potential influence of RNA secondary structure on termination, in vitro transcription experiments were carried out in the presence of nucleoside analogs that differentially influence RNA hairpin formation. Thus, termination was evaluated in the presence of inosine-5' -triphosphate (ITP), which has a destabilizing effect on GC base pair formation, as well as 5iodocytidine-5'-triphosphate (ICTP), a cytidine analog that stabilizes GC pairing. In these experiments, ITP or 


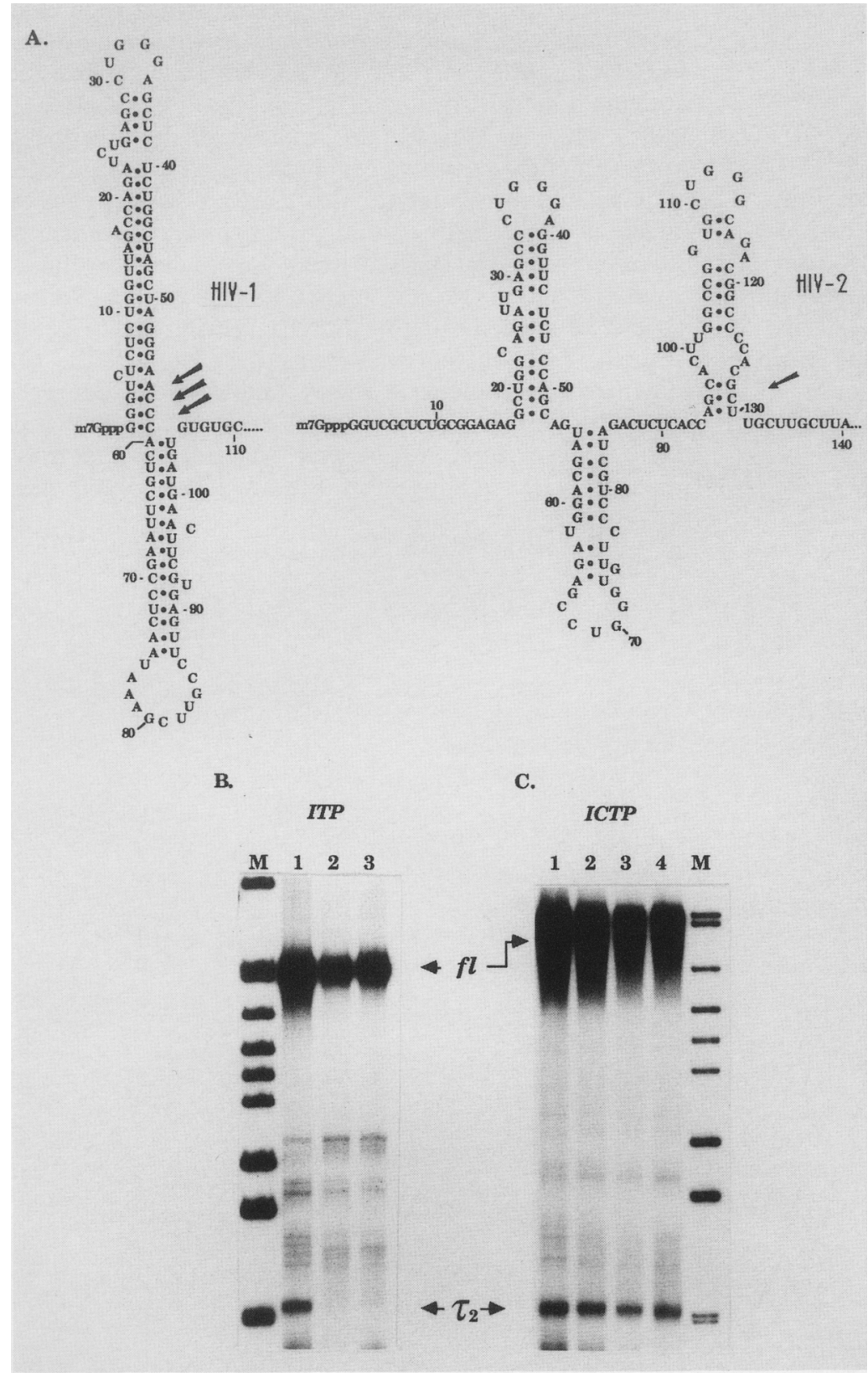

Figure 8. Evidence that RNA secondary structure contributes to termination in vitro. $(A)$ Position of the terminated transcripts (arrows) relative to potential RNA stem-loop structures in the $5^{\prime}$-untranslated leader regions of the HIV-1 and HIV-2 promoters. $(B)$ Incorporation of ITP selectively inhibits synthesis of the 130-nucleotide HIV-2 transcript. EcoRI-cut pLAV2C (HIV-2) templates were incubated with the nuclear extract supplemented with $250 \mu \mathrm{M}$ CTP and ATP, $12.5 \mu \mathrm{M} \mathrm{UTP}$, and either $100 \mu \mathrm{M}$ GTP (lane 1) or $100 \mu \mathrm{M}$ GTP and 500 $\mu \mathrm{M}$ ITP (lanes 2,3), and runoff transcripts were analyzed as described in Methods. The position of the 240-nucleotide runoff transcript (fl) and the 130-nucleotide terminated transcript $\left(\tau_{2}\right)$ are indicated with arrows. Size markers $(M)$ are $M s p I-$ cleaved pBR322 DNA. (C) Incorporation of ICTP in runoff transcripts. Transcription experiments were carried out as described above, except that nuclear extracts were supplemented with $250 \mu \mathrm{M}$ GTP and ATP, $12.5 \mu \mathrm{M}$ UTP, and $100 \mu \mathrm{M}$ CTP, incubated alone (lane 1 ) or with 100,250 , or 500 $\mu M$ ICTP (lanes $2-4$, respectively). Transcription reactions were incubated for either $15 \mathrm{~min}(B)$ or $20 \min (C)$ at $30^{\circ} \mathrm{C}$.
ICTP was added at a three- to fivefold molar excess of guanosine or cytosine levels, respectively. As shown in Figure 8B, incorporation of ITP effectively prevented formation of the 130-nucleotide HIV-2 transcript, without significantly affecting synthesis of the 240-nucleotide runoff transcript. Titration experiments confirm that ITP acts in a dose-dependent manner (data not shown). Thus, GTP is absolutely required for termination in a reaction that cannot be substituted by ITP. This requirement suggests that termination may be specified by a signal that is created during transcription elongation and thus is recognized as RNA rather than DNA. In contrast, incorporation of ICTP into HIV-2 transcripts had no ap- parent effect on termination efficiency in the nuclear extract (Fig. 8C), revealing that some RNA base substitutions are tolerated if they do not have a detrimental effect on hairpin formation. We conclude that the 130nucleotide RNA transcript is generated in a reaction that requires GTP and possibly appropriate RNA secondary structure formation. Although these experiments do not formally discriminate between the importance of potential RNA-RNA versus RNA-DNA structures, existing evidence that the formation of an RNA stem-loop structure is required for trans-activation in vivo (Muesing et al. 1987; Feng and Holland 1988) supports the contention that RNA hairpin formation is a 
critical structural requirement for synthesis of the short RNAs in vitro.

\section{Short HIV-2 transcripts are positioned by an orientation-dependent downstream element}

The data described above indicate that the site of termination might be determined by the location of the most distal RNA stem-loop structure from the HIV-2 promoter. To further analyze the role of HIV-2 downstream sequences in the termination reaction, a synthetic oligodeoxynucleotide corresponding to most of the third stem-loop $(+101$ to +126$)$ was inserted in either orientation downstream of a pHIV-2/LUC + 101 3'-deletion mutant. Analysis of the +101 recombinants in the sarkosyl-treated H.4 extract revealed that the oligodeoxy- nucleotide restored appropriate termination when positioned in the correct orientation downstream of the +101 mutant $(+101$ co; Fig. 9A, lane 4) but failed to provide a termination signal from the inverse orientation $(+101$ io, lane 6). The orientation dependence of this element supports the evidence obtained with ribonucleoside analogs that the downstream signal is recognized as RNA. Furthermore, the terminated transcript observed with mutant +101 co is $\sim 7$ nucleotides longer than the wild-type terminated transcript (Fig. 9B), as would be expected if the short transcript size is determined by the distance between the promoter and the downstream element as the recombinant introduces a short 7-bp linker element (Fig. 9, diagram). As shown in Figure 9C, similar results were obtained when these mutants were analyzed in the nuclear extract, con-

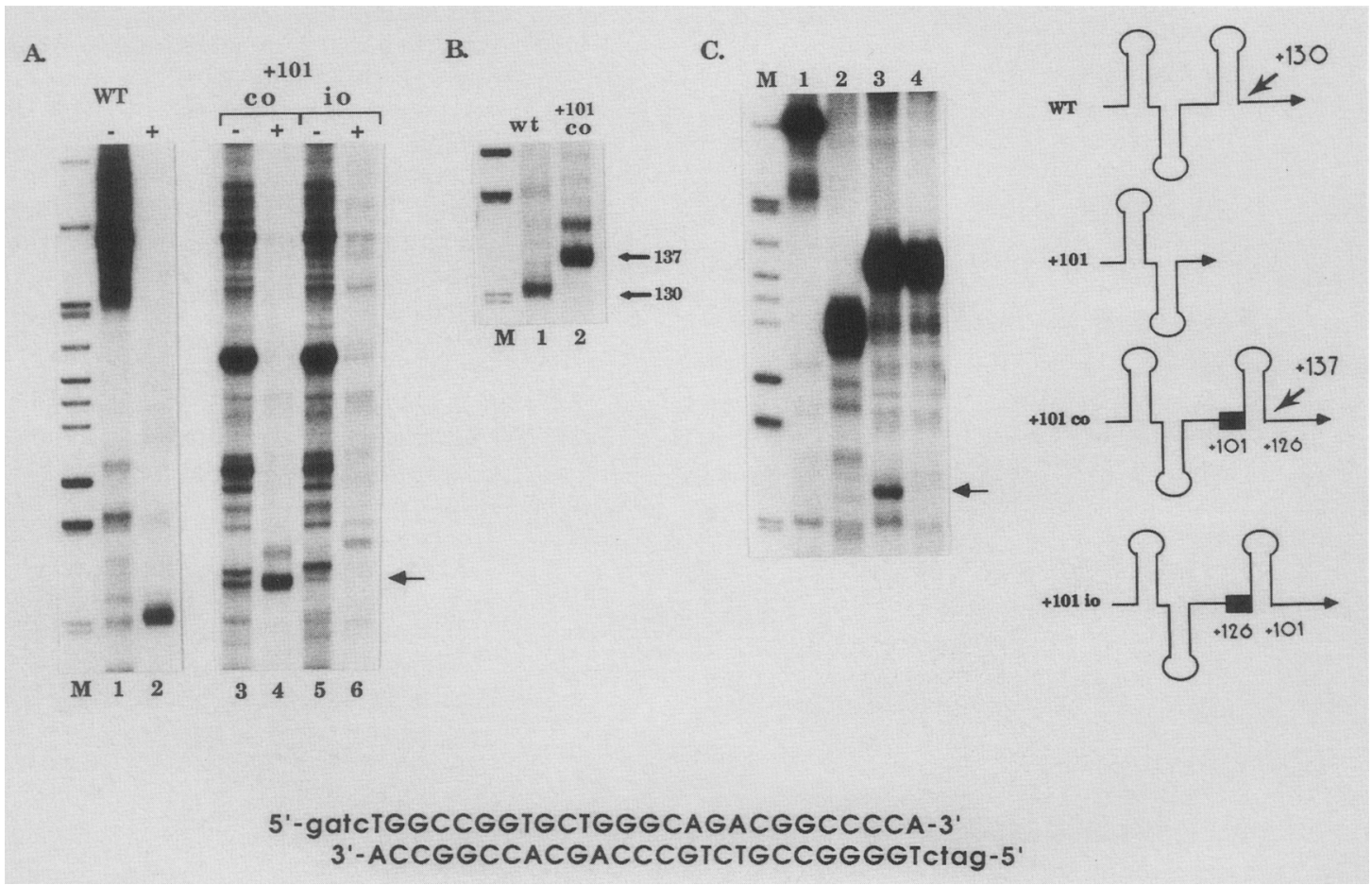

Figure 9. Short HIV-2 transcripts are positioned by an orientation-dependent downstream element. $(A)$ Analysis of recombinant promoters carrying a 26-bp oligodeoxynucleotide insert (bottom) downstream of the termination-deficient $3^{\prime}$-deletion mutant pHIV-2/LUC + 101. Transcription reactions contained $500 \mathrm{ng}$ of supercoiled DNA templates and $100 \mu \mathrm{g}$ H.4 extract in either the absence of sarkosyl (lanes $1,3,5$ ) or presence of $0.10 \%$ sarcosyl (lanes $2,4,6$ ). The plasmid templates were pLAV2C [wild-type (WT), lanes 1,2)], pHIV-2/LUC + 101 co, (lanes 3,4), and pHIV-2/LUC +101 io (lanes 5,6$)$. The short transcript seen with pHIV-2/LUC +101 co is indicated with an arrow. $(B)$ Side-by-side comparison of terminated transcripts from the wild-type (wt) and pHIV-2/LUC +101 co promoters. Transcription reactions were performed using $500 \mathrm{ng}$ of supercoiled pLAV2C (lane 1) or pHIV-2/LUC $+101 \mathrm{co}$, (lane 2) DNA, and $100 \mu \mathrm{g}$ of $\mathrm{H} .4$ extract supplemented with $0.10 \%$ sarkosyl. The position of the 130 -nucleotide wild-type terminated transcript and the 137-nucleotide transcript from the recombinant template are indicated. $(C)$ Analysis of the pHIV-2/LUC +101 recombinant promoters in the HeLa nuclear extract. Transcription templates $(500 \mathrm{ng})$ linearized at the $X b a \mathrm{I}$ site were incubated with $100 \mu \mathrm{g}$ nuclear extract for $15 \mathrm{~min}$ at $30^{\circ} \mathrm{C}$. (Lanes $1-4$ ) Reactions contained pHIV-2/LUC, pHIV-2/LUC + 101, pHIV-2/LUC + 101 co, and pHIV-2/LUC + 101 io, respectively. The arrow indicates the position of the 137-nucleotide RNA seen with pHIV-2/LUC +101 co. Size markers $(M)$ are $M s p I$-digested pBR322 DNA. (Right) Diagram depicts position and orientation of RNA secondary structure in the HIV-2 leader for the wild-type and mutant promoters; the BamHI linker sequence is indicated by a black box, and arrows designate positions of the 130- and 137-nucleotide terminated transcripts. 


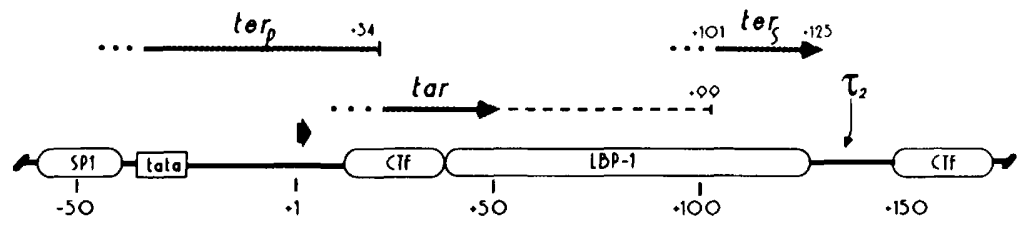

Figure 10. Delineation of transcription control elements at the HIV-2 promoter. The 5 '-untranslated leader region of HIV-2 contains three distinct but overlapping elements that (1) recognize DNA-binding transcription factors LBP-1 and CTF/NF I; (2) mediate the transcriptional response to Tat (TAR); and (3) position the site of termination $\left(T_{E} R_{S}\right)$. The orientation dependence

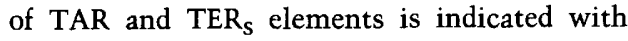
arrows. Sequences critical to Tat trans-activation are indicated with a bold arrow and map to the promoter-proximal RNA hairpin structure, although a modulatory effect was also observed with sequences further downstream to position +83 (Jakobovitz et al. 1988) or +99 (Emerman et al. 1987). The HIV-2 promoter has been implicated in this study with a possible role in specifying termination (TERp).

firming that the downstream sequences function only in the correct orientation (Fig. 9C, lanes 3,4) and give rise to a transcript larger than that of the wild-type promoter (lanes 1,3). Thus, the central portion of the third HIV-2 hairpin depicted in Figure 8A, and not the bottom portion of the stem, appears to be recognized specifically in the termination reaction. Experiments are currently under way to evaluate the potential contributions of the first and second HIV-2 RNA structures to this process in vitro.

We conclude that the HIV 5 -untranslated leader regions contain at least three discrete, partially overlapping elements that contribute to regulated HIV expression (Fig. 10). One set of elements specifies the binding of LBP-1, a cellular transcription factor that enhances HIV promoter activity (Jones et al. 1988) but does not appear to modulate termination efficiency in vitro. In contrast, the other two elements appear to be determined at the RNA level and include an RNA stem-loop structure [trans-activation response element (TAR)], which specifies the response to the viral Tat transactivator protein, and a distinct RNA sequence [element that determines termination site $\left.\left(T_{E R}\right)\right]$, which acts in concert with the promoter to create the short RNA polymerase II transcripts $\left(\tau_{2}\right)$. Both TER ${ }_{S}$ and TAR elements function exclusively in one orientation (Fig. 9 and Rosen et al. 1985, respectively), indicating that in addition to structure, sequences within the RNA are specifically required for both termination and trans-activation function. The different locations of the TER $R_{S}$ element/s) downstream of the HIV-1 and HIV-2 promoters appear to dictate the positioning of distinctly sized short transcripts from these two promoters. Analysis of deletion and recombinant HIV-2 promoters, as well as comparison of the differences between the HIV-2 promoters and AdMLP, introduces the possibility that elements within the HIV promoter [termination element at the promoter $\left.\left(T_{E R}\right)\right]$ may be required specifically for termination and further supports a model in which HIV downstream sequences function to nucleate the termination site.

\section{Discussion}

Transcription induction of HIV promoter activity by the Tat transactivator protein requires a distinctive orientation- and position-dependent control domain that is located within the HIV 5'-untranslated leader region. Run-on transcription experiments in isolated nuclei revealed an apparent block to elongation within this region of the HIV-1 promoter, resulting in short 55- to 59 nucleotide HIV-1 transcripts that were detected in vivo in the absence of Tat (Kao et al. 1987). The in vitro transcription experiments described in this paper provide biochemical evidence that short RNA transcripts observed in the absence of Tat arise from either premature termination or cotranscriptional processing of RNA polymerase II transcripts within the promoter-proximal downstream regions of the HIV-1 and HIV-2 promoters. Most interestingly, transcription from both of these viral promoters yields fully elongated RNAs exclusively in most in vitro transcription systems. We demonstrate here that transcription can be differentially modulated in a fractionated extract by the addition of the anionic detergent sarkosyl, which causes a sharp reduction in full-length transcripts and a concomitant production of shorter RNA transcripts that map within the 5 '-untranslated leader regions of the HIV-1 and HIV-2 promoters. The positioning of short RNAs is specified by downstream sequences, giving rise to a family of HIV-1 transcripts from 58 to 61 nucleotides and a single HIV-2 RNA of $\sim 125-130$ nucleotides in length. A similarly sized HIV-2 transcript of 123 nucleotides has also been detected in vivo in the absence of Tat (B.M. Peterlin, pers. comm.l. We show that the short HIV-2 RNA is an authentic RNA polymerase II transcript that can be generated efficiently from either circular or linear HIV-2 DNA templates and is not derived by topoisomerase-induced DNA alterations or post-transcriptional RNA processing events. Furthermore, the 130-nucleotide HIV-2 RNA is stable in vitro, can be detected in pulse-chase experiments prior to formation of full-length runoff 
transcripts, and does not become incorporated into fulllength HIV-2 RNA during lengthy chase intervals. Thus, if the short RNA formed in the nuclear extract requires a processing step, it must be tightly associated with transcription and follow kinetics that are distinct from that observed in sarkosyl-treated extracts.

Experiments involving the titration of fractionated transcription extracts with sarkosyl were based in design on those carried out previously to dissociate the initiation and elongation steps at the AdMLP (Hawley and Roeder 1985). A short 186-nucleotide adenovirus RNA, which is detected only in the presence of sarkosyl, is thought to arise from pausing or termination events. The mechanism involved in sarkosyl-dependent detection of adenovirus RNA is unknown but may involve the selective dissociation of a cellular antiterminator protein, designated TFIIS, from the elongation complex (Reinberg and Roeder 1987). Several notable distinctions were found between the AdMLP and the HIV promoter in the transcription system that was analyzed here. First, short adenovirus RNAs were detected at sarkosyl concentrations as low as $0.05 \%$ and persisted at concentrations as high as $0.40 \%$, whereas termination from both the HIV-1 and HIV-2 promoters was restricted to a narrow range of sarkosyl concentration from 0.05 to $0.15 \%$. Second, full-length adenovirus transcripts persisted at all sarkosyl concentrations, whereas a complete switch was observed between full-length and terminated HIV transcripts at both transitions of the sarkosyl titration curve. The differential response of the adenovirus and HIV promoters to high sarkosyl concentrations suggests that HIV termination requires an additional component that is inactivated by relatively high sarkosyl concentrations. Thus, if TFIIS can bypass HIV termination in most transcription extracts, its dissociation from the elongation complex is not the only step required for appropriate formation of the short RNAs in vitro at the HIV-1 and HIV-2 promoters. Although adenovirus short RNAs are thought to arise by direct termination of transcription, a cotranscriptional processing step similar to that which may contribute to HIV termination (Fig. 4) has not been ruled out. More detailed studies on the HIV transcripts formed in vitro may help to further differentiate between termination and cotranscriptional processing mechanisms.

One intriguing observation made in the in vitro system is that deletion of downstream sequences does not restore full-length transcription, as might be expected from a simple model of a promoter containing a downstream terminator element. Although we speculated previously that deletions would impinge on LBP-1 binding activity and prove detrimental to overall promoter function, it is clear from these studies that the effect on initiation efficiency caused by the loss of LBP-1 binding sites is minimal in this extract, because expression of each of the HIV-2 deletion mutants is indistinguishable from the wild-type promoter in either the absence of sarkosyl or at high concentrations of the detergent. In the range of sarkosyl concentrations under which short RNAs are observed with the wild-type pro- moter, neither short nor full-length transcripts are detected from mutant promoters lacking the downstream region, and the fate of transcripts that were initiated at these mutant promoters prior to sarkosyl addition is unknown. Although $\mathrm{TER}_{\mathrm{S}}$ clearly determines the location of the termination site (Fig. 91, it is possible that this element plays an additional role in the cotranscriptional stabilization of the short HIV-2 RNAs. If so, this stabilizing influence is not established through RNA structure alone, because the short RNAs are not detected from the +101 io promoter (Fig. 9). These results, taken together with the differences observed between HIV-2 and AdMLP, suggest that promoter sequences upstream of +34 determine the response of full-length transcripts to sarkosyl and that removal of downstream sequences is not sufficient to relieve the block created by the termination signal.

A search of crude nuclear transcription extracts revealed that termination could occasionally be detected in the absence of sarkosyl, although the efficiency of termination under these conditions was never as high as that observed in the sarkosyl-treated H.4 extract. The variability among different extracts suggests that termination efficiency is determined by the relative activities of cellular proteins, possibly including TFIIS. The ability to monitor termination in extracts without the complication of added detergents allowed us to test directly the effects of nucleoside analogs on termination efficiency in vitro. We demonstrate that incorporation of inosine nucleotides, which change the RNA base composition and disrupt GC base-pairing in RNA secondary structures, prevents formation of the 130-nucleotide RNA. In contrast, a distinct nucleoside analog, ICTP, which changes RNA base composition but has a stabilizing effect on GC pairing, did not alter termination efficiency in this system. We conclude that GTP must be specifically required for the detection of short RNAs and may contribute in a step that involves specific GC basepairing, RNA sequence recognition, GTP-specific hydrolysis, or some combination of these events. The different effects of these base analogs on termination suggests that RNA secondary structure is required for appropriate termination in vitro. Moreover, sequences downstream of the HIV-2 promoter that correspond to the terminal stem-loop RNA structure (the TER $_{S}$ element) did not generate a terminated transcript when positioned in an orientation inverted from the wild-type promoter. The orientation dependence of TER $\mathrm{T}_{\mathrm{S}}$, along with the distinct sizes of the HIV-1 and HIV-2 terminated transcripts, indicates that $\mathrm{TER}_{\mathrm{S}}$ function may depend on RNA sequence as well as structure. Sequences within this element appear to be distinct from the orientation-dependent downstream element shown recently to be important for termination of c-myc (Bentley and Groudine 1988). A conserved sequence motif, 5'CCCAC(T)GCTT-3', occurs at or near the termination site of both HIV-1 and HIV-2 transcripts and may play a role in TER $_{\mathrm{s}}$ activity.

The data presented here support a model in which short RNA polymerase II transcripts are produced from 
the HIV-1 and HIV-2 promoters in the absence of Tat or cellular transcription inducers and also indicate the existence of an efficient cellular mechanism that bypasses this process to produce full-length RNAs. We envision that the cellular antitermination activity is used by many HIV transcription-induction mechanisms that do not involve Tat and do not require HIV downstream sequences, including activation of the long terminal repeat (LTR) by phorbol ester tumor promoters and human cytomegalovirus immediate-early genes (Davis et al. 1987; Nabel and Baltimore 1987; Tong-Starksen et al. 1987). It remains to be determined whether termination is circumvented directly or whether efficient formation of short RNAs is only possible in conjunction with a low initiation rate, such that increases in its frequency are sufficient to overcome this process. Thus, two distinct routes to circumvent termination appear to exist: one that is cellular and does not require downstream sequences and one that requires an RNA hairpin structure and is mediated by the viral Tat protein. The synergistic effects observed in vivo between Tat and various cellular activator proteins suggest that both types of regulatory mechanisms are accommodated simultaneously at the promoter. The possibility that Tat acts indirectly by modulating the function of cellular proteins such as TFIIS seems unlikely at first glance, because Tat function absolutely requires the TAR element located downstream of the HIV-1 and HIV-2 promoters. In contrast, the cellular antiterminator activity does not appear to require HIV-2 downstream sequences (Fig. 6D), and sitedirected mutations within TAR do not influence the synthesis of fully elongated HIV-1 transcripts in vitro (Jones et al. 1988). An alternative model is that Tat is recruited to the promoter through the proximal RNA hairpin and acts from that position to influence the properties of the promoter, possibly by modulating a cellular activity like TFIIS. In this context, it is interesting to note that expression of TFIIS appears to be specifically stabilized and possibly even augmented during HIV-1 infection of human T cell lines (Hamamoto et al. 1988).

At present, it is unclear whether the function of Tat is directly related to the process involved in formation of the short RNAs. The strongest suggestion that these two processes are linked comes from observations that short HIV transcripts detected in vivo in the absence of Tat are not apparent following transactivation (Kao et al. 1987). Furthermore, both the sequence and the structure of the downstream region are required for transactivation in vivo and for formation of short RNA transcripts in vitro. Additional studies will allow us to test this connection further by determining whether TAR sequences of HIV-1 and HIV-2 are required for formation of the short RNAs in vitro.

The HIV RNA stem-loop structures appear to carry out dual roles in acting with the promoter to specify termination and mediate the response to Tat. For HIV-1, a single hairpin structure may contribute to both termination and Tat activation (Cullen 1986; Peterlin et al. 1986; Wright et al. 1986; Muesing et al. 1987). In contrast, termination at the HIV-2 promoter is strongly in- fluenced by sequences that include the distal hairpin structure, whereas Tat seems to act primarily on the proximal RNA structure (Emerman et al. 1987; Jakobovitz et al. 1988). The observation that $\mathrm{TER}_{\mathrm{S}}$ is conserved between HIV-1 and HIV-2, but does not form a critical part of TAR on HIV-2, indicates that the short RNAs actually may play a role that is useful to the virus early in infection. The possibility that Tat acts through a promoter-proximal RNA structure to antiterminate transcription invokes a model reminiscent of that for induction of the lysogenic bacteriophage $\lambda$ (for review, see Roberts 1988). Expression of the $\lambda$ early genes encoding the $\mathrm{N}$ and $\mathrm{Q}$ proteins results in transcription antitermination through position and orientation-dependent promoter-proximal sequences, designated nut and qut, through which the $\mathrm{N}$ and $\mathrm{Q}$ proteins function, respectively. Relatively short RNA hairpin structures within the early promoter-proximal regions appear to be important for antitermination (Barik et al. 1987), and although $\mathrm{N}$ and nut sequences function well with heterologous promoters, Q protein function, like Tat, has not yet been fully separated from its cognate promoter (Somasekhar and Szybalski 1983). Our observations that a cotranscriptional RNA processing activity might be responsible for 3' end formation (Fig. 4) suggests that termination at the HIV promoters might resemble more closely that seen for the histone genes (for review, see Birnstiel et al. 1985). Thus, transcripts formed in the absence of Tat may terminate at positions distal to the TAR, TER region, and be processed subsequently to create the short $\tau$ mRNAs.

Finally, the exact role of the HIV promoters in the formation of the short HIV RNAs remains to be established. Similar promoter-specific effects on premature termination have been implicated for the human c-myc gene (Bentley and Groudine 1988), although it is unclear at present which aspect of the $\mathrm{P} 2$ promoter is involved in this process. Promoter-specific effects have also been implicated in appropriate 3 ' end formation of the human U1 and U2 snRNAs (Hernandez and Weiner 1986; Neuman deVegvar et al. 1986). Most interestingly, the basal HIV promoter activity in vivo correlates more closely with the properties of the HIV promoters seen in sarkosyl-treated transcription extracts rather than untreated HeLa cell extracts, which have been optimized for synthesis of full-length transcripts. As a consequence, regulation of transcription at a step immediately following initiation may be a phenomenon that is much more common to RNA polymerase II promoter activity in vivo than is presently appreciated. This possibility is further suggested by the recent experiments of Rougvie and Lis (1988), which demonstrate that a block to elongation efficiency exists immediately downstream of the Drosophila hsp70 promoter that can be overcome in vivo by treatment of isolated nuclei with very high concentrations of sarkosyl. Further analysis of the termination extracts described in this paper should provide revealing insights into the mechanism of HIV termination, as well as its modulation by cellular and viral regulatory proteins. 


\section{Methods}

\section{Plasmid constructions}

The construction of plasmids pLTR/CAT and pLTR/CAT $\Delta H$, which contain HIV-1 LTR sequences $1-630$ to either +182 or +80 , relative to the start of transcription, respectively) upstream of the CAT gene, was described previously (Peterlin et al. 1986). Plasmid pLAX, which contains the AdMLP, has also been described (Dynan and Tjian 1983). Plasmids pLAV2B and pLAV2C were derived from HIV-2 cDNA clones (Emerman et al. 1987) and contain all (pLAV2B) or part (pLAV2C) of HIV-2 $\mathrm{U} 3$ region with the complete $\mathrm{R}$ region (nucleotides +1 to +175 ) plus an extensive poly(A) tract. pLG-2 was constructed by inserting HIV-2 sequences between the SpeI site (position -311 ) and an EcoRI site (following the poly(A) tract) into the $X b a I$ and $E c o$ RI sites of pGEM-1. Plasmids containing deletions of the HIV-2 downstream sequences were created by treating EcoRI-digested pLG-2 with nuclease Bal31 for varying times followed by the addition of synthetic BamHI linkers. Plasmid DNA was isolated from a mixture of transformed cells, restricted with BamHI, and treated with Klenow Escherichia coli DNA polymerase prior to HindIII digestion and DNA fragment isolation. Fragments of appropriate size were inserted upstream of the CAT gene in plasmid pLCl (Toohey et al. 1986) such that both the HindIII and BamHI sites were regenerated upon ligation. The precise endpoints of the HIV-2 deletions were determined by sequence analysis. For constructs containing the oligodeoxynucleotide insertions, a plasmid bearing the HIV-2 promoter deleted of sequences beyond +101 was digested with $B a m H I$, treated with Klenow DNA polymerase, and ligated to HindIII linkers $\left(5^{\prime}\right.$-dCCAAGCTTGG-3'), which also regenerated a BamHI site. The promoter of this plasmid was then isolated as a HindIII fragment and ligated between the luciferase and CAT genes of plasmid pLUC-CAT. The construct used for further modification contained the HIV-2 promoter in the correct orientation for the expression of the luciferase gene. Insertion mutants were then created by ligating annealed oligodeoxynucleotides (for sequence, see Fig. 9) into the unique BamHI site downstream of the HIV-2 promoter, and the orientation of each insertion was determined by sequence analysis.

\section{Preparation and fractionation of HeLa cell extracts}

HeLa cells were harvested at a density of $5 \times 10^{5}$ cells $/ \mathrm{ml}$ and whole-cell or nuclear extracts were prepared as described (Dynan and Tiian 1983). Extracts were desalted by chromatography on $\mathrm{P}-10$ resin or dialysis against TM buffer containing 0.1 M KCl [50 mM Tris- $\mathrm{HCl}$ (pH 7.9), $12.5 \mathrm{~mm} \mathrm{MgCl}_{2}, 1$ mM EDTA, $1 \mathrm{mM}$ dithiothreitol (DTT), 20\% vol/vol glycerol, and $\mathrm{KCl}$, as indicated]. Termination was monitored using either an unfractionated HeLa nuclear extract $(5 \mathrm{mg} / \mathrm{ml}$; Figs. 7 and 8$)$ or a fractionated HeLa whole-cell extract (for the sarkosyl addition experiments). The whole-cell extract (700 mg, $5 \mathrm{mg} / \mathrm{ml}$ ) was applied at $70 \mathrm{ml} / \mathrm{hr}$ to a $53-\mathrm{ml}$ heparin-agarose column equilibrated with TM buffer containing $0.1 \mathrm{M} \mathrm{KCl}$. After washing with three column volumes of TM containing $0.1 \mathrm{M}$ $\mathrm{KCl}$, bound protein was step eluted with three column volumes of TM containing $0.4 \mathrm{M} \mathrm{KCl}$ at a flow rate of $80 \mathrm{ml} / \mathrm{hr}$, and $4-\mathrm{ml}$ fractions were collected. The salt concentration of individual fractions was monitored by conductivity and protein elution was monitored by Bradford staining. Protein-containing fractions eluting at $0.4 \mathrm{M} \mathrm{KCl}$ were pooled $(16 \mathrm{ml} ; 1 \mathrm{mg} / \mathrm{ml})$ and dialyzed against TM containing $0.1 \mathrm{M} \mathrm{KCl}$. This pooled fraction, designated H.4, was used for all experiments in which sarkosyl was used. In a separate experiment, heparin-agarose fractions eluting between 350 and $400 \mathrm{~mm} \mathrm{KCl}$ were also found to be responsive to sarkosyl, whereas fractions eluting between 250 and $350 \mathrm{~mm} \mathrm{KCl}$ were not responsive.

\section{In vitro transcription reactions}

For all runoff transcription experiments, HIV-2 promoter DNA templates (pLAV2C) were linearized with EcoRI, HIV-1 promoter plasmids (pLTR-1/CAT) were cut with EcoRI, and AdMLP templates (pLAX) were digested with BamHI. Transcription reactions, unless otherwise noted in the figure legend, contained $25 \mathrm{mM}$ Tris- $\mathrm{HCl}(\mathrm{pH} 7.9), 50 \mathrm{mM} \mathrm{KCl}, 6.25 \mathrm{~mm}$ $\mathrm{MgCl}_{2}, 10 \mathrm{~mm}$ phosphocreatine, $0.5 \mathrm{~mm}$ EDTA, $10 \%$ glycerol, $2 \%$ polyvinyl alcohol, $500 \mathrm{ng}$ plasmid DNA, $250 \mu \mathrm{M}$ each ATP, GTP, and CTP, $12.5 \mu \mathrm{M}$ cold UTP, $\left.5 \mu \mathrm{Ci}\left[\alpha^{-32}\right)\right] \mathrm{UTP}(800 \mathrm{Ci} /$ mmolel, and $25 \mu \mathrm{l}$ extract in a final volume of $50 \mu \mathrm{l}$. In control experiments, the use of labeled GTP in the place of UTP gave identical transcription and termination reaction products. Extracts were preincubated as described in Figure 1, and nucleotides were then added to initiate transcription. When appropriate, sarkosyl (n-lauroylsarcosine; Sigma) was added to the reaction $30 \mathrm{sec}$ after the addition of nucleotides. Addition of sarkosyl in as little time as $5 \mathrm{sec}$ or as long as $45 \mathrm{sec}$ after nucleotide addition gave identical results. Reactions were then incubated at $30^{\circ} \mathrm{C}$ for either $15 \mathrm{~min}$ (nuclear extract) or $30 \mathrm{~min}$ (H.4). When indicated, $\alpha$-amanitin was added to the preincubation mix at a final concentration of $2.0 \mu \mathrm{g} / \mathrm{ml}$. Transcription reactions were terminated by the addition of $90 \mu \mathrm{l}$ of $1.0 \%$ SDS, $20 \mathrm{~mm}$ EDTA, $200 \mathrm{~mm} \mathrm{NaCl}$, and $250 \mu \mathrm{g} / \mathrm{ml}$ yeast RNA. The mixtures were then extracted once with phenol/chloroform $(1: 1, \mathrm{vol} / \mathrm{vol})$, and the nucleic acids were precipitated with ethanol. The RNA pellets were resuspended in $300 \mathrm{~mm}$ sodium acetate $(\mathrm{pH} 5.2)$ and $0.2 \%$ SDS, reprecipitated from ethanol, resuspended in $6 \mu \mathrm{l} 80 \%$ formamide, $10 \mathrm{~mm} \mathrm{NaOH}, 1 \mathrm{~mm}$ EDTA, $0.1 \%$ bromphenol blue, and $0.1 \%$ xylene cyanol and heat denatured for $10 \mathrm{~min}$ at $85^{\circ} \mathrm{C}$. Labeled RNA transcripts were separated by electrophoresis on $6 \%$ denaturing polyacrylamide gels and visualized by exposure of the dried gels to Kodak X-Omat AR film with an intensifying screen.

Reactions that examined the kinetics of appearance of the sarkosyl-induced transcript were carried out following the preincubation and initiation conditions described above, after which sarkosyl was added to $0.10 \%$ and the reactions were incubated further at $30^{\circ} \mathrm{C}$ for either $5,10,20$, or $30 \mathrm{~min}$. To determine whether newly synthesized transcripts were subject to RNA processing activities, in vitro transcription reactions were carried out as normal, with the exception that sarkosyl was added to $0.10 \%$ either 10 or $20 \mathrm{~min}$ after initiation of transcription and incubated for an additional $30 \mathrm{~min}$ before being stopped. The pulse-chase experiment contained $30 \mu \mathrm{M}$ each ATP, GTP, and CTP and $1.3 \mu \mathrm{M}\left[\alpha^{-32} \mathrm{P}\right] \mathrm{UTP}(600 \mathrm{Ci} / \mathrm{mmole})$ during the 45 -sec pulse, after which the concentration of all four ribonucleotides was increased to $1 \mathrm{mM}$. Reactions were then incubated for varying amounts of time /as indicated in the figure legend) and processed as described above. Based on two separate pulse-chase experiments, the rate of transcription in the nuclear extract was at least 200 nucleotides/min. Transcription reactions containing ITP (Sigma) were performed at the usual nucleotide concentrations, except that GTP levels were set at $100 \mu \mathrm{M}$, which yielded the same amount of transcript as a normal transcription reaction. ITP was then added as indicated in the legend to Figure 8 . In the absence of exogenous GTP, the transcription efficiency dropped to $25 \%$ of that normally obtained, indicating that low levels of nucleotides were present in the extract. Thus, ITP/GTP ratios are an overestimate of the actual ratios present in the transcription reactions. ICTP (Sigma) reactions were carried out as described in Figure 
8. Experiments carried out with extracts lacking exogeneous guanine or cytidine nucleotides confirmed that both ITP and ICTP were efficiently incorporated into full-length transcripts.

\section{Nuclease 11 analysis}

In vitro transcription reactions were performed as above, with the exception that all four nucleotides were present at a concentration of $250 \mu \mathrm{M}$ and labeled nucleotide was omitted. The templates for the transcription reactions were either HindIIIcleaved plasmid pLTR-1/CAT $\Delta \mathrm{H}$ (HIV-1) or EcoRI-cleaved plasmid pLAV2C (HIV-2). Reactions were terminated by the addition of $30 \mu \mathrm{l}$ of $10 \mathrm{M}$ ammonium acetate and $3.5 \mu \mathrm{l} 5.07$ $\mathrm{mg} / \mathrm{ml}$ of yeast RNA, followed by phenol/chloroform extraction and ethanol precipitation. The nucleic acids were resuspended and treated for $15 \mathrm{~min}$ at $37^{\circ} \mathrm{C}$ with 2 units of RQ-1 DNase (Promega) and 80 units RNasin (Promega) in a 50- $\mu \mathrm{l}$ reaction containing $40 \mathrm{~mm}$ Tris- $\mathrm{HCl}$ (pH 7.9), $10 \mathrm{mM} \mathrm{NaCl}, 6 \mathrm{~mm}$ $\mathrm{MgCl}_{2}$. SDS was added to $0.5 \%$ and the mixture incubated 15 min at $37^{\circ} \mathrm{C}$ after the addition of $2.5 \mu \mathrm{l}$ of a $20 \mathrm{mg} / \mathrm{ml}$ solution of proteinase $\mathrm{K}$. Reaction mixtures were extracted with phenol/ chloroform, and nucleic acids were precipitated twice from ethanol. For 3 '-end nuclease S1 analysis, $5 \mu \mathrm{g}$ of pLTR/CAT was digested with RsaI and incubated with 9 units T4 DNA polymerase $\left(2.5 \mathrm{~min}, 37^{\circ} \mathrm{C}\right)$ in a buffer of $33 \mathrm{~mm}$ Tris acetate $(\mathrm{pH}$ 7.9), $66 \mathrm{~mm}$ potassium acetate, $10 \mathrm{~mm} \mathrm{MgCl}_{2}, 0.5 \mathrm{~mm}$ DTT, and $100 \mu \mathrm{g} / \mathrm{ml}$ bovine serum albumin. After incubation, $2.0 \mu \mathrm{l}$ of $1 \mathrm{~mm}$ each dTTP, dCTP, and dGTP, $12.5 \mu \mathrm{M}$ dATP, and 20 $\mu \mathrm{Ci}\left[\alpha^{-32} \mathrm{P}\right] \mathrm{dATP}(3000 \mathrm{Ci} / \mathrm{mmole})$ was added and the reaction was incubated $20 \mathrm{~min}$ at $11^{\circ} \mathrm{C}$. The fill-in reaction was then chased with the addition of $1.0 \mu \mathrm{l}$ of $2.0 \mathrm{mM}$ dATP (10 min, $\left.11^{\circ} \mathrm{C}\right)$. The HIV- $1(-4$ to +182$)$ and HIV $-2(-4$ to +175$)$ probes were isolated following a second restriction digest. Approximately 45 bases of each probe were labeled to a sp. act. of $\sim 2 \times 10^{6} \mathrm{cpm} / \mu \mathrm{g}$. In vitro transcripts were hybridized at $53^{\circ} \mathrm{C}$ with $6 \times 10^{4} \mathrm{cpm}$ probe overnight in a $15-\mu 1$ reaction consisting of $40 \mathrm{~mm}$ PIPES (pH 6.4), 80\% formamide, $400 \mathrm{~mm}$ $\mathrm{NaCl}$, and $1 \mathrm{~mm}$ EDTA. Nuclease $\mathrm{S} 1$ digestion $\left(30 \mathrm{~min}, 37^{\circ} \mathrm{C}\right)$ was performed by the addition of $100 \mu \mathrm{l}$ of a solution containing $150 \mathrm{U} / \mathrm{ml}$ enzyme in a buffer of $50 \mathrm{~mm}$ sodium acetate (pH 4.6), $250 \mathrm{mM} \mathrm{NaCl}, 4.5 \mathrm{~mm} \mathrm{ZnCl}_{2}$, and $5 \%$ glycerol. The reactions were terminated by treatment with proteinase $\mathrm{K}$ and SDS, and protected fragments were processed as for transcription reactions.

\section{RNA and DNA stability experiments}

Both DNA and RNA stability experiments were carried out in the $\mathrm{H} .4$ extract under the in vitro transcription conditions described above, except that labeled UTP was omitted. For DNA stability experiments, the labeled fragment was identical to that described for the nuclease S1 experiments, consisting of HIV- 2 sequences between -4 and +175 . The stability of HIV-2 transcripts was determined using appropriately initiated 240nucleotide RNA labeled in a runoff transcription reaction that contained the EcoRI-cleaved pLAV2C DNA template, and the HeLa H.4 fraction without added sarkosyl. The labeled HIV-2 RNA was isolated by phenol/chloroform extraction and ethanol precipitation, and aliquots of the RNA were reincubated for 15 min at $30^{\circ} \mathrm{C}$ in the $\mathrm{H} .4$ extract, without or with $0.1 \%$ sarkosyl. Subsequent workup and analysis of the RNA was as described for in vitro transcription reactions.

\section{Acknowledgments}

We thank Paul Luciw and Matija Peterlin for their enthusiasm and encouragement, Marian Waterman for the pLUC/CAT vector, and Bev Emerson for tea and critical reading of the manuscript. We are especially grateful to Fernando Echeverri for culturing HeLa cells and thank all of the members of the Jones and Emerson labs for helpful discussions on this project. This work was funded by a grant from the National Institutes of Health (GM-38166). M.G.T. was supported by a grant from the California Universitywide Task Force on AIDS [R87SAL001\}, and K.J. is a Pew Scholar in the Biomedical Sciences supported by the Pew Charitable Trust.

\section{References}

Ackerman, S., D. Bunick, R. Zandomeni, and R. Weinmann. 1983. RNA polymerase II ternary transcription complexes generated in vitro. Nucleic Acids Res. 11: 6041-6064.

Baek, K-H., K. Sato, R. Ito, and K. Agarwal. 1986 . RNA polymerase II transcription terminates at a specific DNA sequence in a HeLa cell-free reaction. Proc. Natl. Acad. Sci. 83: $7623-7627$.

Barik, S., B. Ghosh, W. Whalen, D. Lazinski, and A. Das. 1987. An antitermination protein engages the elongating transcription apparatus at the promoter-proximal recognition site. Cell 50: 885-899.

Bentley, D.L. and M. Groudine. 1986. A block to elongation is largely responsible for decreased transcription of c-myc in differentiated HL60 cells. Nature 321: 702-706.

- 1988. Sequence requirements for premature termination of transcription in the human c-myc gene. Cell 53: 245-256.

Birnstiel, M.L., M. Busslinger, and K. Strub. 1985. Transcription termination and $3^{\prime}$ processing: The end is in sight Cell 41: 349-359.

Cai, H. and D.S. Luse. 1987. Transcription initiation by RNA polymerase II in vitro: Properties of preinitiation, initiation, and elongation complexes. J. Biol. Chem. 262: 298-304.

Chung, J., D.J. Sussman, R. Zeller, and P. Leder. 1987. The c-myc gene encodes superimposed RNA polymerase II and III promoters. Cell 51: 1001-1008.

Cullen, B.R. 1986. Trans-activation of human immunodeficiency virus occurs via a bimodal mechanism. Cell 46: 973 982.

Davis, M.G., S.C. Kenney, J. Kamine, J.S. Pagasno, and E-S Huang. 1987. Immediate-early gene region of human cytomegalovinus trans-activates the promoter of human immunodeficiency virus. Proc. Natl. Acad. Sci. 84: 8642-8646.

Dedrick, R.L., C.M. Kane, and M.J. Chamberlin. 1987. Purified RNA polymerase II recognizes specific termination sites during transcription in vitro. I. Biol. Chem. 262: 90989108.

Dinter, H., R. Chiu, M. Imagawa, M. Karin, and K.A. Jones. 1987. In vitro activation of the HIV-1 enhancer in extracts from cells treated with a phorbol ester tumor promoter. EMBO I. 6: 4067-4071.

Dynan, W.S. and R. Tiian. 1983. Isolation of transcription factors that discriminate between different promoters recognized by RNA polymerase II. Cell 32: 669-680.

Eick, D. and G. Bornkamm. 1987. Transcriptional arrest within the first exon is a fast control mechanism in c-myc gene expression. Nucleic Acids Res. 14: 8331-8346.

Emerman, M., M. Guyader, L. Montagnier, D. Baltimore, and M.A. Muesing. 1987. The specificity of the human immunodeficiency virus type 2 transactivator is different from that of human immunodeficiency virus type 1. EMBO $I$. 6: $3755-3760$.

Feng, S. and E.C. Holland. 1988. HIV-1 Tat trans-activation requires the loop sequence within TAR. Nature 334: 165167. 
Frankel, A.D., D.S. Bredt, and C.O. Pabo. 1988. Tat protein from human immunodeficiency virus forms a metal-linked dimer. Science 240: 70-73.

Friedman, D.I., M.J. Imperiale, and S.L. Adhya. 1987. RNA 3' end formation in the control of gene expression. Annu. Rev. Genet. 21: 453-488.

Green, M.H., J. Buss, and P. Gariglio. 1975. Activation of nuclear RNA polymerase by sarkosyl. Eur. $I$. Biochem. 53: $217-225$.

Hamamoto, Y., S. Hirashima, S. Natori, N. Yamamoto, and N. Kobayashi. 1988. Augmentation and stable expression of a novel transcription factor SII in CD4-positive cells on infection with human immunodeficiency virus type-1 (HIV-1). Biochem. Biophys. Res. Commun. 155: 1346-1352.

Hauber, J. and B.R. Cullen. 1988. Mutational analysis of the trans-activation responsive region of the human immunodeficiency virus type I long terminal repeat. J. Virol. 62: 673679.

Hawley, D.K. and R.G. Roeder. 1985. Separation and partial characterization of three functional steps in transcription initiation by human RNA polymerase II. $/$. Biol. Chem. 260: $8163-8172$.

- 1987. Functional steps in transcription initiation and reinitiation from the major late promoter in a HeLa nuclear extract. J. Biol. Chem. 262: 3452-3461.

Hernandez, N. and A.M. Weiner. 1986. Formation of the $3^{\prime}$ end of U1 snRNA requires compatible snRNA promoter elements. Cell 47: 249-258.

Jakobovitz, A., D.H. Smith, E.B. Jakobovitz, and D.J. Capon. 1988. A discrete element $3^{\prime}$ of human immunodeficiency virus 1 (HIV-1) and HIV-2 mRNA initiation sites mediates transcriptional activation by an HIV trans activator. Mol. Cell. Biol. 8: 2555-2561.

Jones, K.A., J.T. Kadonaga, P.A. Luciw, and R. Tjian. 1986. Activation of the AIDS retrovirus promoter by the cellular transcription factor, Spl. Science 232: 755-759.

Jones, K.A., P.A. Luciw, and N. Duchange. 1988. Structural arrangements of transcription control domains within the $5^{\prime}$ untranslated leader regions of the HIV-1 and HIV-2 promoters. Genes Dev. 2: 1101-1114.

Kao, S.-Y., A.F. Calman, P.A. Luciw, and B.M. Peterlin. 1987. Antitermination of transcription within the long terminal repeat of HIV-1 by Tat gene product. Nature 330: 489-493.

Kawakami, K., C. Scheidereit, and R.G. Roeder. 1988. Identification and purification of a human immunoglobulin enhancer-binding protein (NF-kB) that activates transcription from a human immunodeficiency virus type 1 promoter in vitro. Proc. Nat1. Acad. Sci. 85: 4700-4704.

Mok, M., A. Maderious, and S. Chen-Kiang. 1984. Premature termination by human RNA polymerase II occurs temporally in the adenovirus major late transcriptional unit. Mol. Cell. Biol. 4: 2031-2040.

Muesing, M.A., D.H. Smith, and D.J. Capon. 1987. Regulation of mRNA accumulation by a human immunodeficiency virus trans-activator protein. Cell 48: 691-701.

Nabel, G. and D. Baltimore. 1987. An inducible transcription factor activates expression of human immunodeficiency virus in T cells. Nature 326: 711-713.

Neuman de Vegvar, H.E., E. Lund, and J.E. Dahlberg. 1986. 3' end formation of Ul snRNA precursors is coupled to transcription from snRNA promoters. Cell 47: 259-266.

Peterlin, B.M., P.A. Luciw, P.J. Barr, and M.D. Walker. 1986. Elevated levels of mRNA can account for the trans-activation of human immunodeficiency virus (HIV). Proc. Natl. Acad. Sci. 83: 9734-9738.

Platt, T. 1986. Transcription termination and the regulation of gene expression. Annu. Rev. Biochem. 52: 339-372.

Reinberg, D. and R.G. Roeder. 1987. Factors involved in specific transcription by mammalian RNA polymerase II: Transcription factor IIS stimulates elongation of RNA chains. J. Biol. Chem. 262: 3331-3337.

Reines, D., D. Wells, M. Chamberlin, and C. Kane. 1987. Identification of intrinsic termination sites in vitro for RNA polymerase II within eukaryotic gene sequences. $I$. Mol. Biol. 196: 299-312.

Roberts, J.W. 1988. Phage lambda and the regulation of transcription termination. Cell 52: 5-6.

Rosen, C.A., J.G. Sodroski, and W.A. Haseltine. 1985. The location of cis-acting regulatory sequences in the human $\mathrm{T}$ cell lymphotrophic virus type III (HTLV-III/LAV) long terminal repeat. Cell 41: 813-823.

Rougvie, A.E., and I.T. Lis. 1988. The RNA polymerase II molecule at the $5^{\prime}$ end of the uninduced hsp 70 gene of $\mathrm{D}$. melanogaster is transcriptionally engaged. Cell 54: 795-804.

Somasekhar, G. and W. Szybalski. 1983. Mapping the Q-utilization site (qut) required for antitermination of late transcription in bacteriophage lambda. Gene 26: 291-294.

Tong-Starksen, S.E., P.A. Luciw, and B.M. Peterlin. 1987. Human immunodeficiency virus long terminal repeat responds to T-cell activation signals. Proc. Natl. Acad. Sci. 84: 6845-6849.

Toohey, M.G., K.L. Morley, and D.O. Peterson. 1986. Multiple hormone-inducible enhancers as mediators of differential transcription. Mol. Cell. Biol. 6: 4526-4538.

Wright, C.M., B.K. Felber, H. Paskalis, and G.N. Pavlakis. 1986. Expression and characterization of the trans-activator of HTLV-III/LAV virus. Science 234: 988-992.

Wu, F.K., J.A. Garcia, D. Harrich, and R.B. Gaynor. 1988. Purification of the human immunodeficiency virus type 1 en hancer and TAR binding proteins EBP-1 and UBP-1. EMBO I. 7: 2117-2129. 


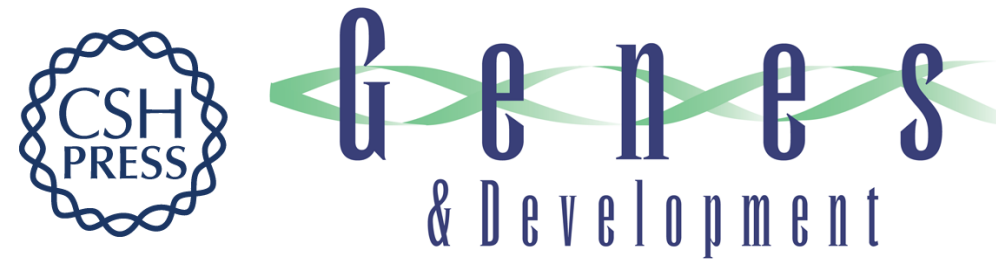

\section{In vitro formation of short RNA polymerase II transcripts that terminate within the HIV-1 and HIV-2 promoter-proximal downstream regions.}

M G Toohey and $\mathrm{K}$ A Jones

Genes Dev. 1989, 3:

Access the most recent version at doi:10.1101/gad.3.3.265

References This article cites 45 articles, 18 of which can be accessed free at: http://genesdev.cshlp.org/content/3/3/265.full.html\#ref-list-1

License

Email Alerting Service

Receive free email alerts when new articles cite this article - sign up in the box at the top right corner of the article or click here.

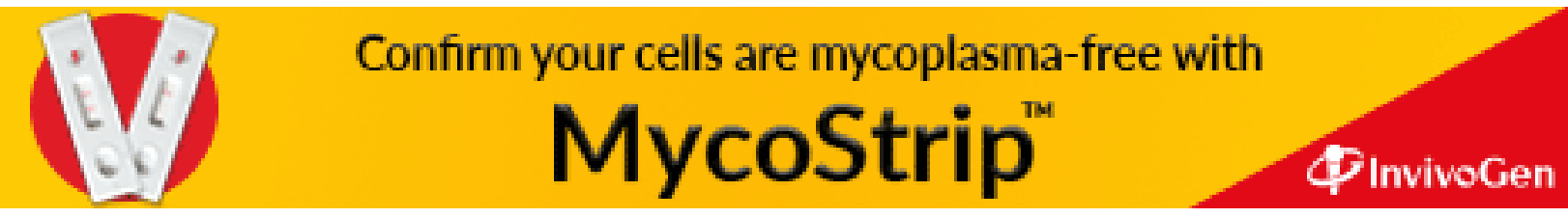

